\author{
Claudio Ruggieri \\ claudio.ruggieri@usp.br \\ University of São Paulo \\ Dept. of Naval Arch. and Ocean Engineering \\ PNV - EPUSP \\ 05508-030 São Paulo, SP, Brazil
}

\section{A Micromechanics Approach to Assess Effects of Constraint on Cleavage Fracture Toughness: a Weibull Stress Model}

This work describes an engineering methodology incorporating the statistics of microcracks and a probability distribution of the (local) fracture stress to assess the effects of constraint loss and weld strength mismatch on crack-tip driving forces. One purpose of this investigation is to establish a definite fracture assessment framework capable of providing robust correlations between toughness data measured using small, laboratory specimens to large, complex structural components with varying crack configurations and loading modes (tension vs. bending). Another purpose is to verify the effectiveness of the proposed methodology building upon a local fracture parameter, here characterized by the Weibull stress, in structural integrity assessments of cracked components including steel weldments. Overall, the exploratory applications conducted here lend strong support to use Weibull stress based procedures in defect assessments of cracked structures.

Keywords: cleavage fracture, local approach, Weibull stress, constraint effect, weld strength mismatch

\section{Introduction}

The fundamental importance of cleavage fracture behavior in structural integrity assessments has stimulated a rapidly increasing amount of research on predictive methodologies for quantifying the impact of defects in load-bearing materials such as, for example, cracks in critical weldments of high pressure vessels. Such methodologies play a key role in repair decisions and life-extension programs for in-service structures (e.g., aerospace, nuclear and offshore structures) while, at the same time, ensuring acceptable safety levels during normal operation. For ferritic materials at temperatures in the ductile-to-brittle transition (DBT) region, fracture by transgranular cleavage along well defined, low index crystallographic planes (see, e.g., Averbach, 1965 and Tetelman and McEvily, 1967) is the dominant operative micromechanism. This failure mode potentially limits the load bearing capacity of the structure as local crack-tip instability may trigger catastrophic failure at low applied stresses with little plastic deformation.

Conventional methods of fracture mechanics analysis employ a one-parameter characterization of loading and toughness, most commonly the $J$-integral or the corresponding value of the Crack Tip Opening Displacement (CTOD, $\delta$ ). The approach correlates unstable crack propagation in different cracked bodies based on the similarity of their respective near-tip stress and strain fields provided small scale yielding (SSY) conditions prevail. Under these conditions, near-tip plastic deformation is well-contained with plastic zones vanishingly small compared to the relevant physical dimensions in fracture specimens and structural components such as crack length, remaining ligament, etc. (see, e.g., the review by Hutchinson, 1983). However, the stress histories that develop in the near-tip region of a macroscopic crack in engineering structures containing shallow cracks are more often of different character than those for the high constraint SSY condition. At increasing levels of loading and deformation, large scale yielding conditions (LSY) gradually develop at the crack tip region, which relax the near-tip stress fields below the SSY levels, particularly for moderate-to-low hardening materials. The decreased level of crack-tip constraint and the strong interaction of remote loading with near-tip plasticity potentially cause significant elevations (factors exceeding 3 5) in the elastic-plastic fracture toughness for shallow crack configurations of ferritic steels tested in the transition region, where transgranular cleavage triggers macroscopic fracture. The enormous practical implications of this apparent increased toughness of common ferritic steels in low-constraint conditions, particularly in defect assessment and repair decisions of in-service structures, have spurred a flurry of new analytical, computational and experimental research over the past years.

More recent efforts within the framework of continuum fracture mechanics have focused on the development of two-parameter fracture methodologies to describe the full range of Mode I, elasticplastic crack-tip fields with varying near-tip stress triaxiality. Within these methodologies, $J$ sets the size scale over which large stresses and strains develop, while the second parameter, such as the $T$ stress (Al-Ani and Hancock, 1991; Betegon and Hancock, 1991; Du and Hancock, 1991; Parks, 1992) or the nondimensional $Q$ parameter (O'Dowd and Shih, 1991, 1992), scales the near-tip stress distribution. The approach also enables the introduction of a toughness locus for a specific material and temperature in connection with a $J-Q$ driving force trajectory for each crack geometry; here, the toughness locus for the material is constructed upon determining the $Q$-value at fracture which corresponds to each measured $J_{c}$-value (O'Dowd and Shih, 1991, 1992). However, the large number of fracture specimens and different temperatures needed to construct the $J-Q$ toughness locus greatly complicate direct implementation of this approach to fracture assessments as does the application of the method (which derives from a 2-D framework) to fully 3-D crack geometries. Moreover, such models do not address the strong sensitivity of cleavage fracture to material characteristics at the microlevel nor do they provide a means to predict the effects of constraint and prior ductile tearing on toughness. In particular, the random inhomogeneity in local features of the material causes large scatter in experimentally measured values of fracture toughness $\left(J_{c}, \delta_{c}\right.$ or CTOD). Such features do assessments of structural integrity using laboratory testing of standard specimens and simplified crack configurations to a complex task: what is the "actual" material toughness and how is the scatter in measured values of fracture toughness incorporated in defect assessment procedures? 
The above arguments that continuum fracture mechanics approaches do not suffice to characterize the fracture behavior of fully yielded crack geometries motivated the development of micromechanics models based upon a probabilistic interpretation of the fracture process (most often referred to as local approaches). Attention has been primarily focused on probabilistic models incorporating weakest link statistics to describe material failure caused by transgranular cleavage. In the context of probabilistic fracture mechanics, a limiting distribution describes the coupling of the (local) fracture stress with remote loading (as measured by $J$ or CTOD). A fracture parameter associated with this limiting distribution conveniently characterizes macroscopic fracture behavior for a wide range of loading conditions and crack configurations. Batdorf and Crose (1974), Evans (1978) and Matsuo (1981) first considered models of this type to describe brittle fracture for arbitrary loading. Here, a convenient function describing the number of microcracks per unit volume failing at each value of the local tensile stress is used to arrive at the probability of fracture for a cracked body. Later, Beremin (1983), Wallin et al. (1984a, 1984b, 1986, 1993), Lin et al. (1986), Godse and Gurland (1989), Brückner et al. (1990), among others provided a link between the size of carbide particles dispersed in the material and the inhomogeneous stress fields ahead of a macroscopic crack. They sought to predict the dependence of fracture toughness $\left(K_{I c}\right)$ on material properties and temperature.

Among these earlier research efforts, the work of Beremin (1983) provides the basis for establishing a relationship between the microregime of fracture and macroscopic crack driving forces (such as the $J$-integral) by introducing the Weibull stress $\left(\sigma_{w}\right)$ as a probabilistic fracture parameter. A key feature of the Beremin approach is that $\sigma_{w}$ follows a two-parameter Weibull distribution (Weibull, 1951; Mann et al., 1974) in terms of the Weibull modulus, $m$, and the scale parameter, $\sigma_{u}$. Further idealization postulates that parameter $m$ represents a material property in this model (Mudry, 1987) possibly dependent on temperature but invariant of loading history, which provides a means to correlate fracture toughness for varying crack configurations under different loading conditions. When implemented in a finite element code, the Beremin model predicts the evolution of the Weibull stress with applied load to define conditions leading to (local) material failure. Previous research efforts to develop a transferability model to elastic-plastic fracture toughness values rely on the notion of the Weibull stress as a crack-tip driving force (Ruggieri and Dodds, 1996a, 1996b; Ruggieri, 2001a, 2001b). The central feature in this methodology adopts the simple axiom that unstable crack propagation (cleavage) occurs at a critical value of the Weibull stress; under increased remote loading (as measured by $J$ ), differences in evolution of the Weibull stress reflect the potentially strong variations of near-tip stress fields and crack-tip constraint.

This work describes an engineering methodology incorporating the statistics of microcracks and a probability distribution of the (local) fracture stress to assess the effects of constraint loss and weld strength mismatch on crack-tip driving forces. One purpose of this investigation is to establish a definite fracture assessment framework capable of providing robust correlations between toughness data measured using small, laboratory specimens to large, complex structural components with varying crack configurations and loading modes (tension vs. bending). Another purpose is to verify the effectiveness of the proposed methodology building upon a local fracture parameter, here characterized by the Weibull stress $\left(\sigma_{w}\right)$, in structural integrity assessments of cracked components including steel weldments. Overall, the exploratory applications conducted here lend strong support to use Weibull stress based procedures in defect assessments of cracked structures.

\section{Probabilistic Modeling of Cleavage Fracture}

\section{Description of Scatter in Fracture Toughness Values}

Fracture testing of ferritic steels in the DBT region consistently reveal large scatter in the measured values of cleavage fracture toughness. It is now widely known that such scatter in toughness data is essentially associated with the random location and orientation of fracture-triggering microcracks near the (macroscopic) crack tip (Anderson, 2005). The connection between the local (cleavage) fracture process and extreme value statistics plays the key role in describing the scatter in fracture toughness values. A continuous probability function derived from weakest link statistics conveniently characterizes the distribution of toughness values, $J_{c}$, in the form (Weibull, 1951; Mann et al., 1974).

$$
F\left(J_{c}\right)=1-\exp \left[-\left(\frac{J_{c}-J_{t h}}{J_{0}-J_{t h}}\right)^{\alpha}\right]
$$

which is a three-parameter Weibull distribution with parameters $\left(\alpha, J_{0}, J_{t h}\right)$. Here, $\alpha$ denotes the Weibull modulus (shape parameter), $J_{0}$ defines the characteristic toughness (scale parameter) and $J_{t h}$ is the threshold fracture toughness. In particular, parameter $\alpha$ represents a measure of the scatter in the toughness data; the larger this value, the less scattered is the toughness distribution (Mann et al., 1974).

The threshold fracture toughness is often set equal to zero, $J_{t h}=0$ so that the Weibull function given by Eq. (1) assumes its more familiar two-parameter form in terms of parameters $\left(\alpha, J_{0}\right)$ as

$$
F\left(J_{c}\right)=1-\exp \left[-\left(\frac{J_{c}}{J_{0}}\right)^{\alpha}\right]
$$

The above limiting distribution remains applicable for other measures of fracture toughness such as $K_{I c}$ or CTOD $\left(\delta_{c}\right)$. A central feature emerging from the weakest link distribution expressed by Eq. (2) is that, under SSY conditions, the scatter in cleavage fracture toughness data is characterized by $\alpha=4$ for $K_{I c}$-distributions (Wallin, 1984b; Anderson, 2005) or $\alpha=2$ for $J_{c}$ or $\delta_{c}$-distributions (Minami et al., 1992; Anderson, 2005).

There is still some debate as to whether a two-parameter or three-parameter Weibull distribution should be adopted to describe fracture toughness data. Anderson (2005) provides some objections against Eq. (2) by making formal arguments in favor of nonzero threshold toughness. He notes that the crack driving force must be increased to a certain limit to initiate unstable crack propagation following some amount of plastic work dissipated in breaking atomic bonds and crossing randomly oriented grain boundaries. He also points out that a three-parameter function generally fits better cleavage toughness data. While the merits of such arguments are valid, there also exist some points of criticism to the use of a threeparameter Weibull function. A major drawback is associated with unreliable estimates of the threshold toughness when a conventional statistical procedure, such as the maximum likelihood method, is used to determine parameter $J_{t h}$ (Ruggieri, 1989). For a given set of cleavage toughness values, however, differences in failure probability for both distributions are small. Consequently, the 
present work proceeds by adopting more conventional and simpler two-parameter Weibull distribution throughout the analyses.

\section{The Weibull Stress for Cracked Solids}

To extend the previous methodology to multiaxially stressed, 3-D crack configurations, research efforts have been focused on probabilistic models coupling the micromechanical features of the fracture process (such as the inherent random nature of cleavage fracture) with the inhomogeneous character of the near-tip stress fields. Motivated by the specific micromechanism of transgranular cleavage, a number of such models (most often referred to as local approaches) employ weakest link arguments to describe the failure event. The overall fracture resistance is thus controlled by the largest fracture-triggering particle that is sampled in the fracture process zone ahead of crack front. A convenient statistical description of microcracks then provides the connection between the microregime of fracture and macroscopic (global) behavior to yield a statistical distribution for the (cleavage) fracture stress.

Consider an arbitrarily stressed body where a macroscopic crack lies in a homogeneous material containing randomly distributed flaws as illustrated in Fig. 1(a). The fracture process zone ahead of the crack tip is defined as the highly stressed region where the local operative mechanism for cleavage takes place; this region contains the potential sites for cleavage cracking. For the purpose of developing a probabilistic model for cleavage fracture, divide the fracture process zone ahead of crack tip in $N$ unit volumes statistically independent, $V_{i}, i=1,2, \ldots, N$ subjected to the principal stress $\sigma_{1}$. Each unit volume, $V_{i}$, contains a substantially number of statistically independent microflaws uniformly distributed.

The statistical nature of cleavage fracture underlies a simplified treatment for unstable crack propagation of the configuration represented in Fig. 1(a) based upon weakest link arguments. First, limit attention to the asymptotic distribution for failure of the unit volume and consider each $V_{i}$ divided into small volumes uniformly stressed, statistically independent, $\delta V_{j}, j=1,2, \ldots, n$. Let $p$ denote the probability of failure for the $j$ th volume $\delta V_{j}$. The probability that $k$ failures occur (which correspond to the fracture of $k$ small volume elements $\delta V$ ) is defined in terms of the Binomial distribution (Feller, 1957; Kendall and Stuart, 1967):

$$
P\left(S_{n}=k\right)=\left(\begin{array}{l}
n \\
k
\end{array}\right) p^{k}(1-p)^{n-k} \quad, \quad 0 \leq k \leq n,
$$

where $S_{n}$ denotes the total number of failures that occurred in $n$ volume elements. When $k$ is large and $p$ is small, by the Poisson limit theorem (Feller, 1957; Kendall and Stuart, 1967), the distribution of the number of failures converges to a Poisson distribution with parameter $\mu$ in the form

$$
P\left(S_{n}=k\right)=\frac{e^{-\mu} \mu^{k}}{k !}
$$

where $\mu=k p$ is the expectation (mean value) of the binomial distribution. In particular, the probability that at least one failure occurs is sought. Thus, the failure probability of the unit volume, denoted $P_{0}$, has distribution

$$
P_{0}=P\left(S_{n} \geq 1\right)=1-P\left(S_{n}=0\right)=1-e^{-\mu}
$$
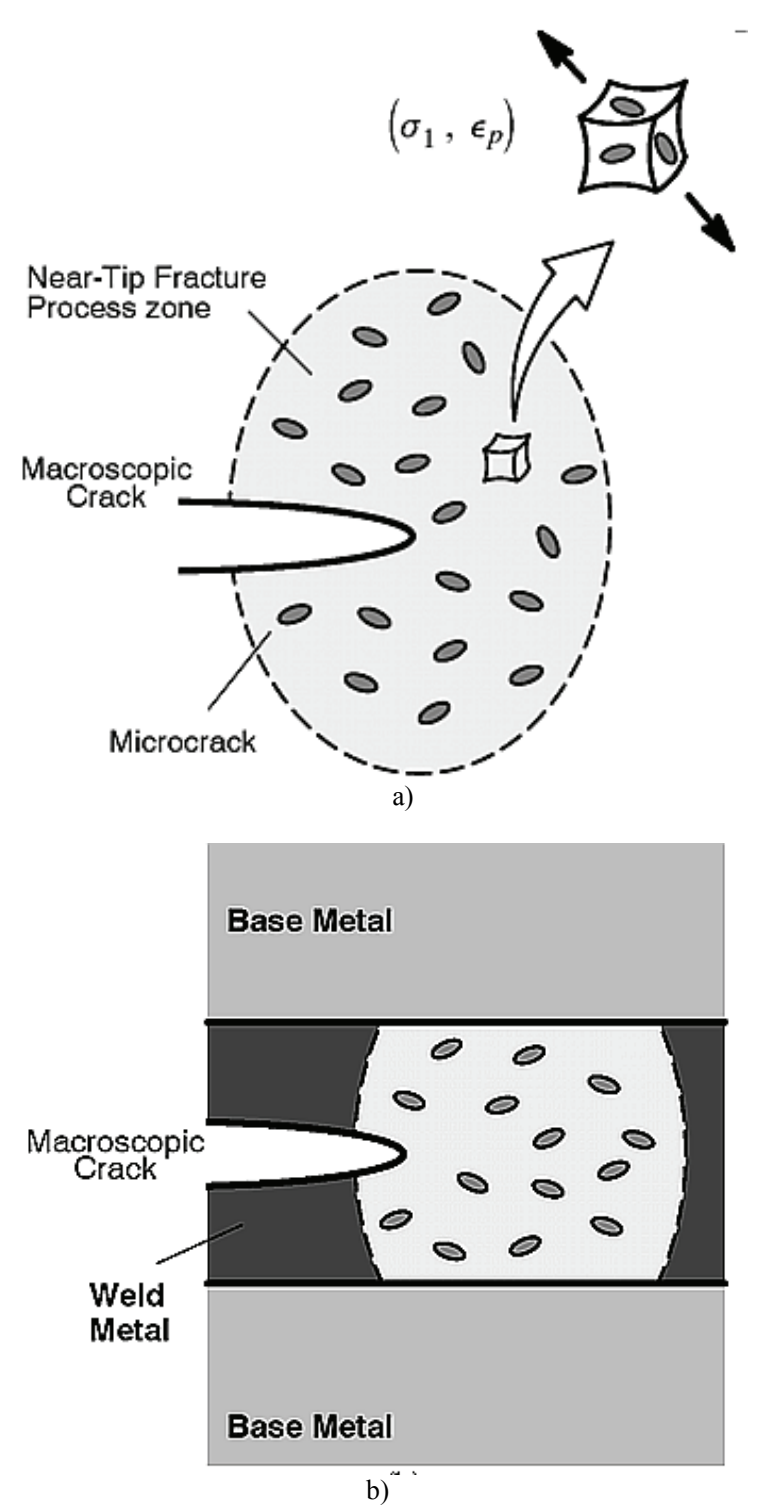

Figure 1. (a) Near-tip fracture process zone ahead a macroscopic crack containing randomly distributed flaws; (b) Schematic of fracture process zone for a macroscopic crack embedded in the weld metal.

To arrive at a limiting distribution for the fracture stress of a cracked solid, an appropriate functional form for the mean $\mu$ is required. The most widely adopted probabilistic model to describe fracture in brittle materials is based upon the weakest link (WL) theory. A central feature emerging from the WL model is the notion that catastrophic failure is driven by unstable propagation of a single critical microflaw or microcrack contained in the unit volume $V$ which allows expressing the "average" number of failures, $\mu$, as

$$
\mu=\int_{l_{c}}^{\infty} g(l) d l
$$

where $l$ is the microcrack size, $l_{c}$ is the critical microcrack size and $g$ represents the microcrack density function. Here, it is understood that the failure probability $p$ depends on the principal stress level, $\sigma_{1}$, acting on $V$, i.e., $p=p\left(\sigma_{1}\right)$. A common assumption adopts an asymptotic distribution for the microcrack 
density in the form $g(l)=\left(\psi_{0} / l\right)^{\xi}$ (Freudenthal, 1968; Evans and Langdon, 1976; Beremin, 1983), where $\xi$ and $\psi_{0}$ are parameters of the distribution. However, previous fundamental work (Averbach, 1965; Tetelman and McEvily, 1967) clearly shows the strong effect of plastic deformation, in the form of inhomogeneous arrays of dislocations, on microcrack nucleation which also contributes to trigger cleavage fracture at the material's microlevel. Based upon direct observations of cleavage microcracking by plastic strain made in ferritic steels at varying temperatures (Brindley, 1970; Lindley et al., 1970; Gurland, J., 1972), the microcrack density can then be further generalized in terms of

$$
g(l)=\varepsilon_{p}^{\gamma(1+\beta)}\left(\frac{\psi_{0}}{l}\right)^{\xi},
$$

where $\varepsilon_{p}$ is the (effective) plastic strain, $\gamma$ and $\beta$ represent parameters defining a power law relationship between the microcrack density and plastic strain as inferred in Lindley et al. (1970).

Now, upon introducing the dependence between the critical microcrack size, $l_{c}$, and (local) stress in the form $l_{c}=\left(K_{I c}^{2} / Y^{2} \sigma_{1}^{2}\right)$, where $Y$ represents a geometry factor and $K_{I c}$ is the critical stress intensity factor, and substituting Eq. (7) into Eq. (6), the mean, $\mu$, resolves to

$$
\mu=\varepsilon_{p}^{\gamma(1+\beta)}\left(\frac{\sigma_{1}}{\Lambda_{0}}\right)^{m}
$$

where parameters $m=2 \xi-2$ and $\Lambda_{0}$ are related to the microcrack distribution with $m$ and $\Lambda_{0}>0$. Using this result in Eq. (5) enables defining the failure probability $P_{0}$ for the unit volume $V$ in the form

$$
P_{0}=1-\exp \left[-\varepsilon_{p}^{\gamma(1+\beta)}\left(\frac{\sigma_{1}}{\sigma_{u}}\right)^{m}\right]=1-\exp \left[-\left(\frac{\tilde{\sigma}_{1}}{\sigma_{u}}\right)^{m}\right]
$$

which is a Weibull distribution with parameters $m$ and $\sigma_{u}$.

Further development in the adopted probabilistic framework requires invoking again weakest link arguments to generalize the previous probability distribution to any multiaxially stressed region, such as the fracture process zone ahead of a macroscopic crack or notch (see Fig. 1(a)). Here, the statistical problem of determining an asymptotic distribution for the fracture strength of the entire solid is equivalent to determining the distribution of the weakest unit volume $V$. The fundamental assumption is that the near-tip fracture process zone consists of $N$ arbitrary and statistically independent, unit volumes $V$. Consequently, the failure probability of the entire cracked solid, $P$, is given by

$$
P=1-\left[1-P_{0}\right]^{N}=1-\prod_{i=1}^{N}\left(1-P_{0}\right)
$$

Substituting Eq. (9) into the above expression and making $N \rightarrow \infty$, the probability distribution of the fracture stress for a cracked solid based upon the WL model results

$$
P=1-\exp \left[-\frac{1}{\Omega_{0}} \int_{\Omega} \varepsilon_{p}^{\gamma(1+\beta)}\left(\frac{\sigma_{1}}{\sigma_{u}}\right)^{m} d \Omega\right]
$$

where $\Omega$ denotes the volume of the near-tip fracture process zone and $\Omega_{0}$ is a reference volume usually taken as unit, i.e., $\Omega_{0}=1$. In the present work, the active fracture process zone is defined as the loci where $\sigma_{1} \geq \lambda \sigma_{y s}$ in which $\lambda \approx 2$ and $\sigma_{y s}$ defines the material's yield stress; results for $\sigma_{w}$ differ little over a relatively wide range of $\lambda$-values for $\lambda \approx 1.5 \sim 2.5$. Such definition for the near-tip fracture process zone bears direct connection with the highly stressed and strained crack-tip region extending over $3 \sim 5$ times the crack-tip opening displacement $(\delta)$ in which transgranular cleavage and microscopic separation processes occur (Hutchinson, 1983).

Following the development presented previously, the Weibull stress, a term coined by the Beremin group (1983) is then given by integration of the principal stress over the fracture process zone in the form

$$
\sigma_{w}=\left[\frac{1}{\Omega_{0}} \int_{\Omega} \varepsilon_{p}^{\gamma(1+\beta)} \sigma_{1}^{m} d \Omega\right]^{1 / m}
$$

from which the probability distribution given by Eq. (11) now takes the form

$$
P\left(\sigma_{w}\right)=1-\exp \left[-\left(\frac{\sigma_{w}}{\sigma_{u}}\right)^{m}\right] .
$$

The above Eq. (13) defines a two-parameter Weibull distribution (Weibull, 1951; Mann et al., 1974) for the Weibull stress in terms of the Weibull modulus $m$ and the scale factor $\sigma_{u}$. In the context of probabilistic fracture mechanics, the Weibull stress, $\sigma_{w}$, emerges as a near-tip fracture parameter to describe the coupling of remote loading with a micromechanics model based upon the statistics of microcracks (weakest link philosophy). A key feature of this methodology is that $\sigma_{w}$ incorporates both the effects of stressed volume (the fracture process zone) and the potentially strong changes in the character of the near-tip stress fields due to constraint loss. The next sections address application of the Weibull stress methodology to predict effects of constraint loss and strength mismatch on cleavage fracture toughness data.

\section{Toughness Scaling Methodology Based Upon the Weibull Stress}

A central objective in developing a probabilistic-based model to describe cleavage fracture lies on the prediction of unstable crack propagation in two different structural components for a wide range of crack configurations and loading modes (tension vs. bending). In fracture mechanics spirit, experimentally measured values of fracture toughness for one configuration (e.g., small laboratory specimens for homogeneous materials and weldments) can be rationally extended to predict unstable crack propagation for other crack configurations, including welded components, based on the attainment of a specified value for the probabilistic-based fracture parameter that triggers cleavage fracture in each specimen even though the corresponding $J(\delta)$-values may differ widely. 
This section introduces the essential features of a toughness scaling methodology (TSM) based upon the Weibull stress to correlate toughness values ( $J_{c}$ or CTOD) across crack configurations with varying geometries and crack-tip constraint levels, including weldments. The presentation begins with the development of a TSM strategy which appears most applicable to assess the effects of constraint and statistical variations on cleavage fracture toughness data in homogeneous materials. Subsequent description focuses on the extension of the TSM approach to bimaterial systems such as center-cracked welds.

\section{TSM for Homogeneous Materials}

To make contact with the correlative character of the present framework, the concept of a toughness scaling model based upon the Weibull stress enables a simplified micromechanics treatment to predict constraint effects on cleavage fracture toughness. As discussed earlier, the central feature of this methodology derives from the interpretation of $\sigma_{w}$ as the crack-tip driving force coupled with the simple axiom that cleavage fracture occurs when $\sigma_{w}$ reaches a critical value, $\sigma_{w, c}$. For the same material at a fixed temperature, the scaling model requires the attainment of a specified value for $\sigma_{w, c}$ to trigger cleavage fracture across different crack configurations even though the loading parameter (measured by $J$ in the present work) may vary widely due to constraint loss. In the probabilistic context adopted here, attainment of equivalent values of Weibull stress in different cracked configurations implies the same probability for cleavage fracture.

Figure 2(a) illustrates the procedure to assess the effects of constraint loss on cleavage fracture behavior needed to scale toughness values for different cracked configurations. The procedure employs $J$ as the measure of macroscopic loading, but remains valid for other measures of remote loading, such as CTOD. Without loss of generality, Fig. 2(a) displays $\sigma_{w}$ vs. $J$ curves for a high constrained configuration (such as a deep notch three-point bend specimen - SE(B)), denoted as configuration $\mathbf{A}$, and a low constraint configuration (such as surface crack specimen under tension loading - SC(T)), denoted as configuration B. Very detailed, nonlinear 3-D finite element analyses provide the functional relationship between the Weibull stress $\left(\sigma_{w}\right)$ and applied loading $(J)$ for a specified value of the Weibull modulus, $m=m_{0}$. Given the $J_{A}$-value for the high constraint fracture specimen, the lines shown on Fig. 2(a) readily illustrate the technique used to determine the corresponding $J_{B}$-value.

\section{TSM for Welded Materials}

TSM outlined above can be extended to assess effects of constraint variations due to weld strength mismatch on cleavage fracture toughness data by adopting the concept of a nondimensional Weibull stress, hereafter denoted $\bar{\sigma}_{w}$, which is defined as $\sigma_{w}$ normalized by the yield stress of the material where fracture takes place. To facilitate development of the TSM incorporating effects of weld strength mismatch, it proves convenient to first define the mismatch ratio, $M_{y}$, as

$$
M_{y}=\frac{\sigma_{y s}^{W M}}{\sigma_{y s}^{B M}}
$$

where $\sigma_{y s}^{B M}$ and $\sigma_{y s}^{W M}$ denote the yield stress for the base metal and weld metal. Consequently, the nondimensional Weibull stress for a bimaterial system such as a welded joint can be defined as

$$
\bar{\sigma}_{w}^{k}=\frac{\sigma_{w}^{k}}{\sigma_{y s}^{k}}
$$

where $k=1,2$ corresponds to the baseplate and weld material. In adopting such nondimensional form for the Weibull stress, it is important to emphasize that the integration appearing in Eq. (12) must be performed over the volume of the fracture process zone for each material, as depicted in Figure 1(b). With the Weibull stress defined in this manner, material points outside the region over which the integration is carried out are (implicitly) assigned a zero probability of cleavage fracture.

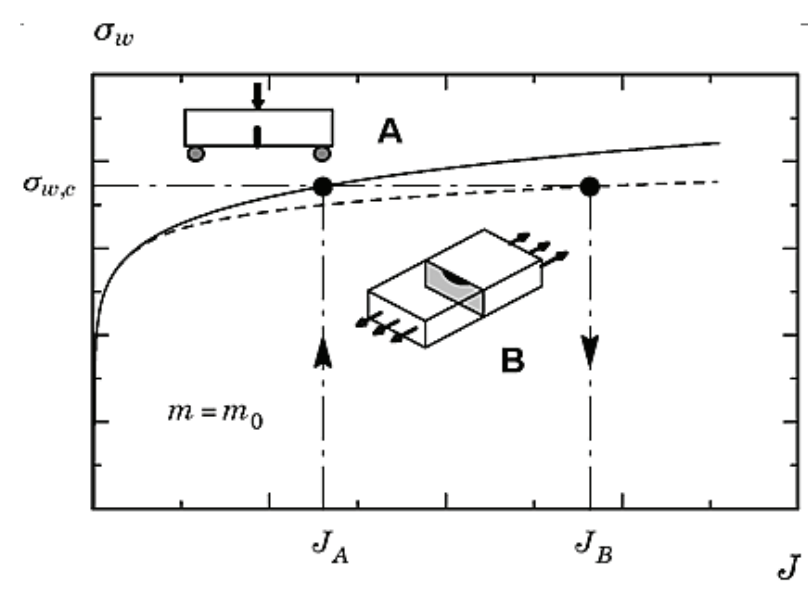

a)

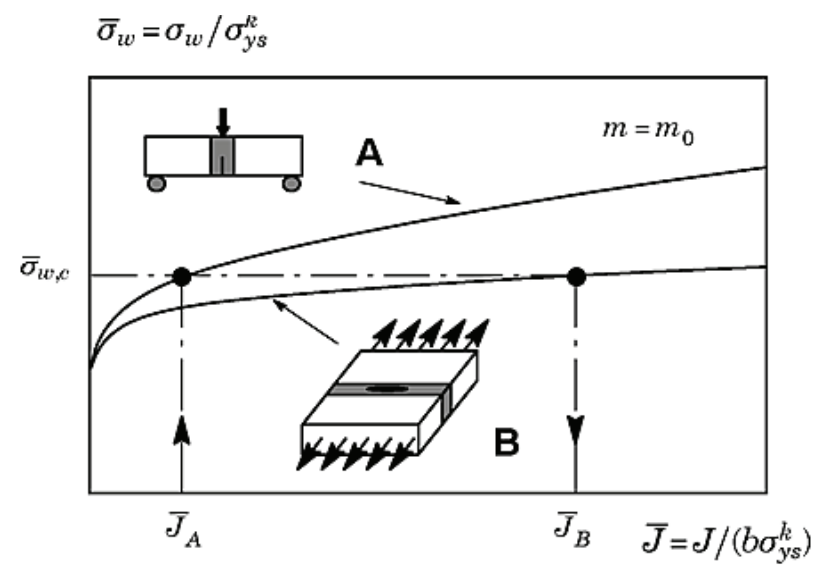

b)

Figure 2. (a) Scaling procedure based on the Weibull stress to correct toughness values for different crack configurations. (b) Scaling procedure based on the normalized Weibull stress to correct toughness values for different mismatch conditions.

Consider now extension of TSM for toughness correlations in welded components. Based upon micromechanics considerations outlined previously, the proposed scaling model requires the attainment of a specified value for the nondimensional Weibull stress, $\bar{\sigma}_{w, c}$, to trigger cleavage fracture in different welded specimens subjected to different levels of crack-tip loading. Figure 2(b) illustrates the procedure to assess the effects of strength mismatch on cleavage fracture behavior needed to scale toughness 
values for cracked configurations with different mismatch conditions based upon the TSM strategy. The procedure employs a nondimensional crack driving force defined by $\bar{J}=J /\left(b \sigma_{y s}^{k}\right)$, where $b$ is the remaining crack ligament as the measure of macroscopic loading, but remains valid for other measures of remote loading, such as CTOD. Without loss of generality, Fig. 2(b) displays $\bar{\sigma}_{w}$ vs. $\bar{J}$ curves for a high constraint, welded configuration (such as a deep notch SE(B) specimen with a centercracked square groove) made with an evenmatch condition $\left(M_{y}=1\right)$, denoted as configuration $\mathbf{A}$, and a welded structural component (such as surface crack specimen under tension loading) made with an overmatch condition $\left(M_{y}>1\right)$, denoted as configuration B. Again, very detailed, nonlinear 3-D finite element analyses provide the functional relationship between the Weibull stress $\left(\bar{\sigma}_{w}\right)$ and applied loading $(\bar{J})$ for a specified value of the Weibull modulus, $m=m_{0}$. Given a measured toughness value at cleavage for the high constraint, evenmatch fracture specimen $\left(\bar{J}_{A}\right)$, the lines shown on Fig. 2(b) readily illustrate the technique used to determine the corresponding $\bar{J}_{B}$-value for the structural welded component.

A key assumption in the above toughness scaling methodology is that parameter $m$ is independent of strength mismatch level, $M_{y}$, or, at least, it can be considered a weak function of the mismatch ratio. For low to moderate levels of weld overmatch $\left(M_{y} \leq 1.2 \sim 1.3\right.$ ), the adopted assumption appears consistent with the development pursued in this work while, at the same time, maintaining the relative simplicity of TSM to welded components given current knowledge. As will be discussed, the adopted engineering procedure is rather effective in predicting the failure strain of a $10 \%$ overmatch wide plate specimen even though its level of crack-tip constraint varies widely from a conventional, laboratory fracture specimen under bending.

\section{Parameter Calibration of the Weibull Modulus, m, Using Toughness Data}

Calibration of the material dependent $m$-parameter, and to a lesser extent parameters $\gamma$ and $\beta$ describing the potential influence of plastic strain on microcrack density, plays a crucial role in applications of the present methodology to assess effects of constraint and statistical variations on cleavage fracture toughness data. In particular, the Weibull modulus, $m$, strongly affects the shape and magnitude of the constraint correction curves upon which the toughness ratio for two different crack configurations is determined (see Fig. 2).

The calibration protocol scheme for parameter $m$ adopts the scaling methodology previously outlined to correct measured toughness distributions for different crack configurations. The procedure extends previous work by Gao et al. (1998) and Ruggieri et al. (2000) to calibrate the Weibull modulus using high constraint (SSY) and low constraint (LSY) fracture toughness data measured at the same temperature and loading rate. Because each measured $J_{c}^{A}$-value is corrected to its equivalent $J_{c}^{B}$-value, the statistical (Weibull) distribution of $J_{c}^{A}$-values is also corrected to an equivalent statistical (Weibull) distribution of $J_{c}^{B}$-values. Consequently, the present scheme defines the calibrated $m$-value for the material as the value that corrects the characteristic toughness
$J_{0}^{A}$ (i.e., the scale parameter of previous Eq. (2)) to its equivalent $J_{0}^{B}$ for two sets of fracture toughness data from different crack configurations and with sufficient differences in the evolution of $\sigma_{w}$ vs. $J$. The procedure can also be extended in straightforward manner to calibrate parameter $m$ for weldments and bimaterial systems.

The following steps describe the key procedures in the adopted calibration scheme for parameter $m$. The next section addresses application of this parameter calibration process for ferritic structural steels, including overmatched welds.

\section{Step 1}

Test two sets of specimens with different crack configurations (A and $\mathbf{B}$ ) in the ductile-to-brittle transition (DBT) region to generate two distributions of fracture toughness data. Select the specimen geometries and the common test temperature to insure different evolutions of constraint levels for the two configurations. No ductile tearing should develop prior to cleavage fracture in either set of tests. For weldments, test two sets of specimens with different strength mismatch conditions (A and $\mathbf{B}$ ) also in the region to generate two distributions of fracture toughness data. Ideally, configuration A should correspond to fracture specimens for the evenmatch condition $\left(M_{y}=1\right)$. Several alternatives to obtain the two sets of toughness values at the same test temperature include: $i$ ) for homogeneous materials, test high constraint deep-notch $\mathrm{SE}(\mathrm{B}) \mathrm{s}$ or $\mathrm{C}(\mathrm{T}) \mathrm{s}$ specimens with $a / W \geq 0.5$ as configuration A. To ensure SSY conditions at fracture, set the specimen size so that $J_{c} \leq b \sigma_{y s} / M$ for each specimen, with the deformation limit, $M$, conservatively set to $\approx 60 \sim 100$ (Nevalainen and Dodds, 1995). For configuration $\mathbf{B}$, use similar size $\mathrm{SE}(\mathrm{B})$ specimens, but with shallow-notches, i.e., $a / W \leq 0.2 \sim 0.25$. These will undergo significant constraint loss when the deep-notch values just satisfy the suggested deformation limit; ii) for weldments, test deep-notch $\mathrm{SE}(\mathrm{B}) \mathrm{s}$ or $\mathrm{C}(\mathrm{T}) \mathrm{s}$ specimens with $a / W \geq 0.5$ and different degrees of weld mismatch. Select the specimen geometries, mismatch conditions and the common test temperature to insure different evolutions of mismatch and constraint levels for the two configurations.

\section{Step 2}

Determine the characteristic toughness value for each data set, $J_{0}^{A}$ and $J_{0}^{B}$, using a standard maximum likelihood estimation procedure (Mann et al., 1974). Alternatively, the Master Curve procedure given by ASTM E-1921 (ASTM, 2008) can be employed with the fracture toughness measure, $K_{J c}$, replaced by $J_{c}$ which enables defining $J_{0}$ in the form

$$
J_{0}=\left[\frac{1}{N_{J}} \sum_{i=1}^{N_{J}} J_{c, i}^{2}\right]^{1 / 2}
$$

where $N_{J}$ is the number of tested specimens for each crack configuration. In the above formulation, it is understood that the threshold fracture toughness, $J_{t h}$, is set equal to zero and the Weibull modulus, $\alpha$, of the corresponding Weibull distribution is assigned a fixed value of 2 . In case limited ductile tearing does develop in some specimens, the corresponding toughness values can 
be treated as censored values by manipulating the Master Curve procedure as above (see ASTM E-1921) in the form

$$
J_{0}=\left[\frac{1}{r} \sum_{i=1}^{N_{J}} J_{c, i}^{2}\right]^{1 / 2}
$$

where $r$ is now the number of tested specimens exhibiting no ductile tearing.

\section{Step 3}

Perform detailed, nonlinear finite element analyses in large geometry change (LGC) setting for the tested specimen geometries. The mesh refinements must be sufficient to ensure converged $\sigma_{w}$

vs. $J$ (or $\bar{\sigma}_{w}$ vs. $\bar{J}$ ) histories for the expected range of $m$-values and loading levels.

\section{Step 4}

4.1 Assume an $m$-value. Compute the $\sigma_{w}$ vs. $J$ (or $\bar{\sigma}_{w}$ vs. $\bar{J})$ trajectories for configurations $\mathbf{A}$ and $\mathbf{B}$ to construct the toughness scaling model relative to both configurations.

4.2 Correct $J_{0}^{A}\left(\bar{J}_{0}^{A}\right)$ to its equivalent $J_{0}^{B}\left(\bar{J}_{0}^{B}\right)$, i.e., the corrected value of the mean toughness for the assumed $m$-value for effects of constraint loss or weld strength mismatch. Define the error of toughness scaling as $R(m)=\left(J_{0, m}^{A}-J_{0}^{A}\right) / J_{0}^{A}$ or $R(m)=\left(\bar{J}_{0, m}^{A}-\bar{J}_{0}^{A}\right) / \bar{J}_{0}^{A}$.

4.3 If $R(m) \neq 0$, repeat substeps $4.1-4.2$ for additional $m$ values. The calibrated Weibull modulus, $m=m_{0}$, makes $R(m)=0$ within a small tolerance.

\section{Numerical Procedures and Computational Models}

\section{Finite Element Models for Homogeneous Fracture Specimens}

Three-dimensional finite element analyses are conducted on different crack configurations which include: (1) a conventional, plane sided $\mathrm{C}(\mathrm{T})$ specimen with $a / W=0.6, \quad B=25 \mathrm{~mm}$ and $W=50 \mathrm{~mm}$; (2) a conventional, plane sided SE(B) specimen with $a / W=0.2, B=25 \mathrm{~mm}, W=50 \mathrm{~mm}$ and $S=4 W$ and (3) a boltloaded surface crack SC(T) specimen with $a / t=0.25, c / a=3$ and $t=25 \mathrm{~mm}$. For the $\mathrm{C}(\mathrm{T})$ and $\mathrm{SE}(\mathrm{B})$ specimens, $a$ is the crack length, $W$ is the specimen width, $B$ is the specimen thickness and $S$ is the bend specimen span. For the $\operatorname{SC}(\mathrm{T})$ specimen, $a$ is the maximum depth of the surface crack, $2 c$ is the length of the semielliptical crack and $t$ is the thickness of the cracked section. Figure 3 shows the geometry and specimen dimensions for the analyzed crack configurations. Joyce and Link (1997) used these specimens to measure the cleavage fracture resistance of an ASTM A515-70 pressure vessel steel.

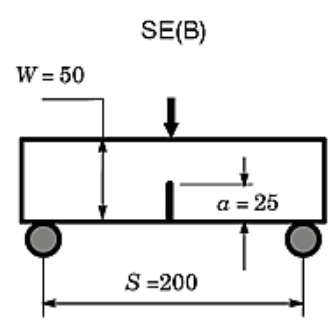

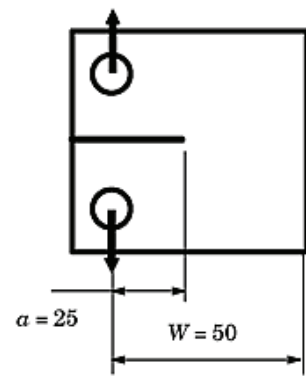

$\mathrm{C}(\mathrm{T})$
Units: $\mathrm{mm}$

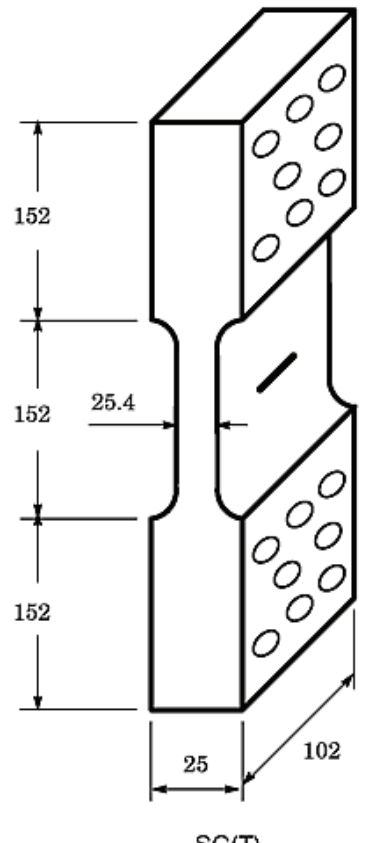

$\mathrm{SC}(\mathrm{T})$
Figure 3. Geometry of tested specimens for A515-70 pressure vessel steel.

Figure 4 displays the finite element model constructed for the 3-D analyses of the SC(T) specimen. Symmetry conditions enable analyses using one-quarter of the 3-D model with appropriate constraints imposed on the symmetry planes. A focused ring of elements surrounding the crack front in the radial direction is used with a small key-hole at the crack tip; the radius of the key-hole, $\rho_{0}$, is $2.5 \mu \mathrm{mm}$. The half-length of the semi-elliptical crack is defined by 20 elements arranged over the (one-half) crack front. The quarter-symmetric, 3-D model for the SC(T) specimens has 25650 nodes and 22800 elements. The models for the $\mathrm{C}(\mathrm{T})$ and SE(B) specimens have similar features and similar levels of mesh refinement. These meshes have 10 variable thickness layers defined over the half-thickness $(B / 2)$; the thickest layer is defined at $Z=0$ with thinner layers defined near the free surface ( $Z=B / 2$ ) to accommodate strong $Z$ variations in the stress distribution. The quarter-symmetric, 3-D models for the $\mathrm{C}(\mathrm{T})$ and SE(B) specimens have 11800 nodes and 9800 elements.

\section{Finite Element Models for Welded Fracture Specimens}

Three-dimensional nonlinear finite element analyses are also conducted on different welded crack configurations which include: (1) a conventional, plane sided $\mathrm{SE}(\mathrm{B})$ specimen with $a / W=0.5$, $B=25 \mathrm{~mm}, W=25 \mathrm{~mm}$ and $S=4 W$ and (2) a clamped surface crack $\mathrm{SC}(\mathrm{T})$ specimen with $a / t=0.24, a / t=8.3, t=25 \mathrm{~mm}$, $2 W=400 \mathrm{~mm}$ and $L=300 \mathrm{~mm}$. For the SE(B) specimens, $a$ is the crack length, $W$ is the specimen width, $B$ is the specimen thickness and $S$ is the bend specimen span. For the SC(T) specimen, $a$ is the maximum depth of the surface crack, $2 c$ is the length of the semielliptical crack, $t$ is the thickness of the cracked section, $2 W$ is the specimen width and $L$ is the specimen length. The weld groove width for both specimen configurations is $2 h=10 \mathrm{~mm}$. Figure 5 shows the geometry and specimen dimensions for the analyzed crack configurations. Minami et al. (1995) used these specimens to measure the cleavage fracture resistance for steel weldments made of an API X80 pipeline steel as described previously. 


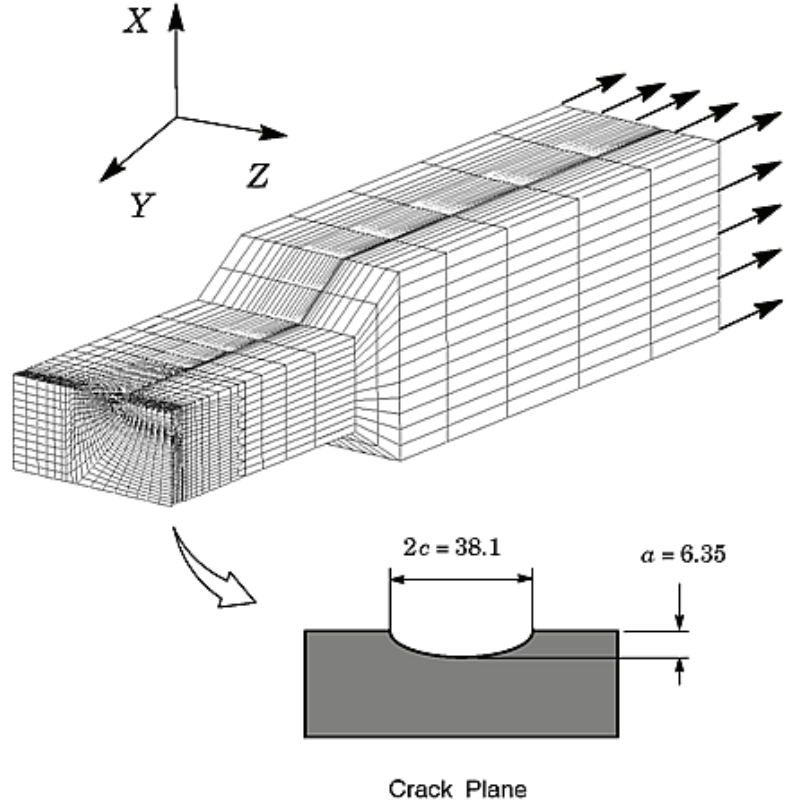

Units: mm

Figure 4. Quarter-symmetric finite element model for the bolt-loaded surface crack specimen.

Figure 6 displays the finite element model constructed for the 3 -D analyses of the SC(T) specimen. Symmetry conditions enable analyses using one-quarter of the numerical model with appropriate constraints imposed on the symmetry planes. Again, a focused ring of elements surrounding the crack front in the radial direction is used with a small key-hole at the crack tip; the radius of the key-hole, $\rho_{0}$, is also $50 \mathrm{~mm}$ with similar levels of refinement along the crack front that closely match the mesh refinement employed in the $\mathrm{SE}(\mathrm{B})$ specimen. The half-length of the semi-elliptical crack is defined by 16 elements arranged over the (one-half) crack front. The quarter-symmetric, 3-D model for the $\mathrm{SC}(\mathrm{T})$ specimens has $\sim 6300 \quad 8$-node, 3D elements $(\sim 7500$ nodes). This finite element model is loaded by displacement increments imposed on the loading points with clamped constraint conditions at the specimen ends. The models for the $\mathrm{SE}(\mathrm{B})$ specimens have similar features and similar levels of mesh refinement. The quarter-symmetric, 3-D meshes have 12 variable thickness layers with $\sim 10000$ 8-node, 3D elements $(\sim 12000$ nodes) defined over the half-thickness $(B / 2)$; the thickest layer is defined at $Z=0$ with thinner layers defined near the free surface $(Z=B / 2)$ to accommodate strong $Z$ variations in the stress distribution.

\section{Material Models and Computational Procedures}

The elastic-plastic constitutive models employed in all analyses reported here follow a $J_{2}$ flow theory with conventional Mises plasticity in large geometry change (LGC) setting. The next section describes numerical analyses for fracture specimens extracted from an A515-70 pressure vessel and an API X80 pipeline steel weld that were tested in the experimental program. Gao et al. (1999) describes the uniaxial stress-strain curve for the A515-70 pressure vessel steel at the test temperature, $T=-7^{\circ} \mathrm{C}$ and $T=-28^{\circ} \mathrm{C}$. Minami et al. (1995) provides the uniaxial true stress vs. logarithm strain curves for the API X80 pipeline steel (base plate and overmatch weld material) at the test temperature, $T=-5^{\circ} \mathrm{C}$. These curves for both materials were used in the finite element computations reported here.
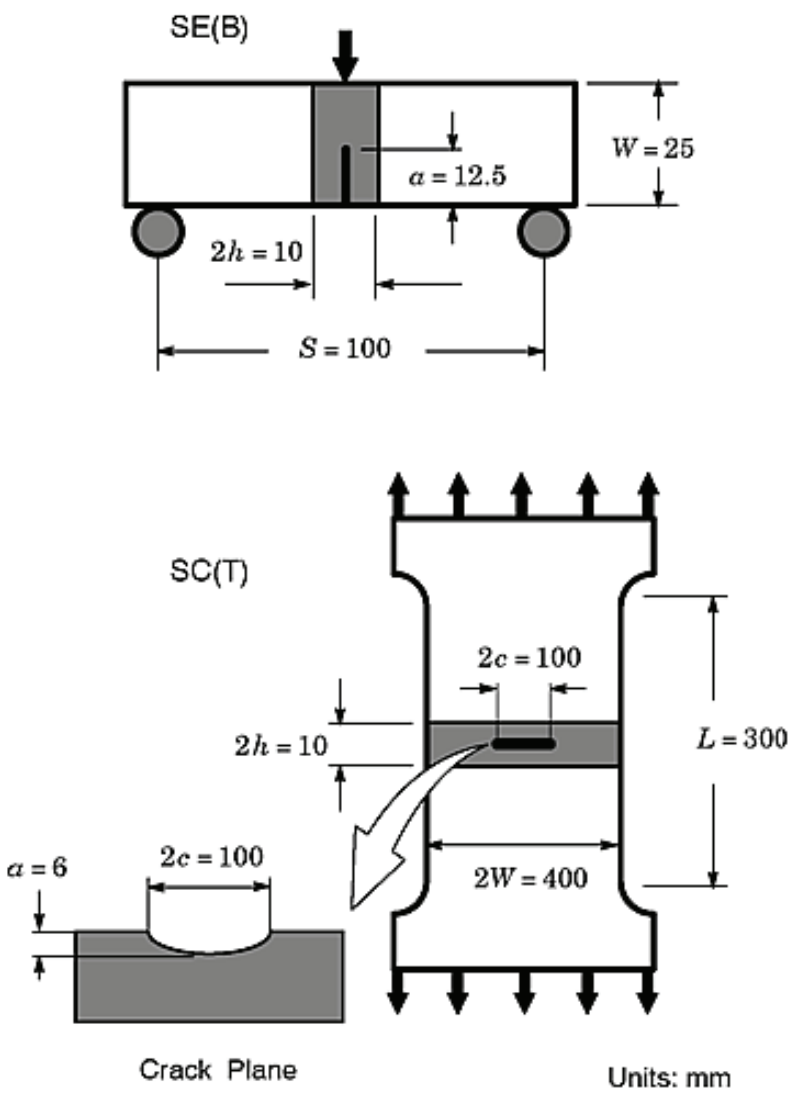

Figure 5. Geometries for the tested welded fracture specimens.
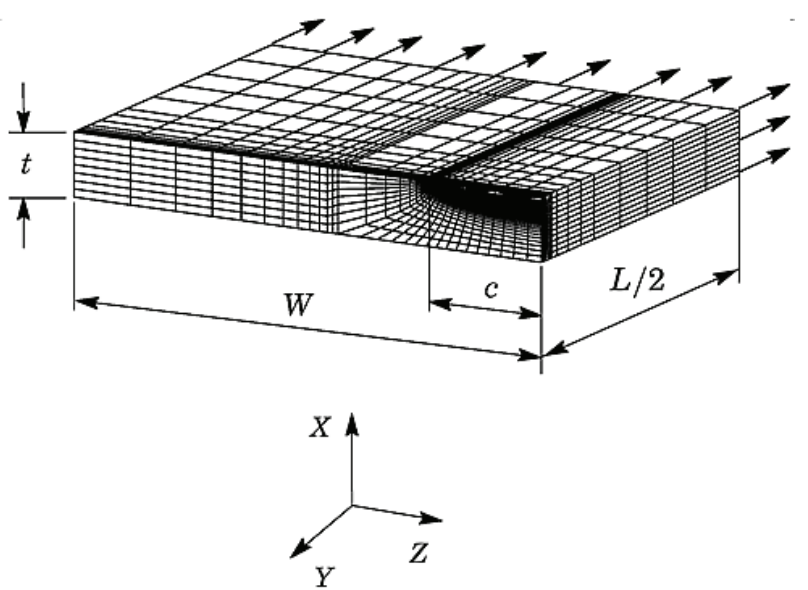

Figure 6. Finite element model for the $\mathrm{SC}(\mathrm{T})$ specimen.

The numerical computations for the cracked configurations reported here are generated using the research code WARP3D (Gullerud et al., 2004). The code incorporates a Mises $\left(J_{2}\right)$ constitutive model in both small-strain and finite-strain framework and solves the equilibrium equations at each iteration using a very efficient, sparse matrix solver highly tuned for Unix and PC based architectures. This sparse solver significantly reduces both memory and $\mathrm{CPU}$ time required for solution of the linearized equations 
compared to conventional direct solvers. A typical 3-D analysis for solution of the fracture models employed in this study runs in two to six hours in a single-processor PC-based workstation. The finite element computations employ a domain integral procedure (Moran and Shih, 1987) for numerical evaluation of the $J$ integral along the crack front. The research code WSTRESS (Ruggieri, 2001) is used to construct $\sigma_{w}$ vs. $J$ ( $\bar{\sigma}_{w}$ vs. $\bar{J}$ ) trajectories for these fracture specimens needed to perform the calibration of parameter $m$.

\section{Cleavage Fracture Predictions for the A515-70 Pressure Vessel Steel}

\section{Fracture Toughness Testing}

Joyce and Link (1997) and Gao et al. (1999) recently reported a series of fracture toughness tests conducted on an ASTM A515 Gr70 pressure vessel steel. The fracture mechanics tests include: (1) a conventional, plane sided $\mathrm{C}(\mathrm{T})$ specimen with $a / W=0.6$, $B=25 \mathrm{~mm}$ and $W=50 \mathrm{~mm}$; (2) a conventional, plane sided SE(B) specimen with $a / W=0.2, \quad B=25 \mathrm{~mm}, \quad W=50 \mathrm{~mm}$ and $S=4 W$ and (3) a bolt-loaded surface crack SC(T) specimen with $a / t=0.25, c / a=3$ and $t=25 \mathrm{~mm}$. The material is an A515-70 pressure vessel steel $\left(280 \mathrm{MPa}\right.$ yield stress at $\left.-7^{\circ} \mathrm{C}\right)$ with relatively high hardening properties $\left(\sigma_{u t s} / \sigma_{y s} \approx 2\right)$. Gao et al. (1999) provides the true stress-logarithmic strain curve at the test temperatures $\left(T=-7{ }^{\circ} \mathrm{C}\right.$ and $\left.T=-28^{\circ} \mathrm{C}\right)$ for this material used in the finite element analyses of the specimens.

Testing of these configurations was performed at $T=-28^{\circ} \mathrm{C}$ for the $\mathrm{C}(\mathrm{T})$ specimens and $T=-7^{\circ} \mathrm{C}$ for the $\mathrm{SE}(\mathrm{B})$ and $\mathrm{SC}(\mathrm{T})$ specimens; these temperatures correspond to the ductile-to-brittle transition behavior for the material. Figure 7(a) provides a Weibull diagram of the measured toughness values for both test temperatures. The solid symbols in the plots indicate the experimental fracture toughness data for the specimens. Values of cumulative probability, $F$, are obtained by ordering the $J_{c}$-values and using $F=(i-0.3) /\left(N_{J}+0.4\right)$, where $i$ denotes the rank number and $N_{J}$ defines the total number of experimental toughness values. The straight lines indicate the two-parameter Weibull distribution, Eq. (1). While the Weibull slopes for the $\mathrm{C}(\mathrm{T})$ and $\mathrm{SE}(\mathrm{B})$ toughness distributions are very similar ( $\alpha \approx 2$ for both distributions), the results clearly demonstrate a strong effect of constraint level on the characteristic toughness, $J_{0}$ (the $J$-value corresponding to $63.2 \%$ failure probability). In contrast, the Weibull slope for the $\mathrm{SC}(\mathrm{T})$ specimen differ significantly ( $\alpha \approx 10$ ) from the $\alpha$-value for the $\mathrm{C}(\mathrm{T})$ and $\mathrm{SE}(\mathrm{B})$ specimens; here, the $\mathrm{SC}(\mathrm{T})$ and shallow crack $\mathrm{SE}$ (B) specimen have similar values for the characteristic toughness.

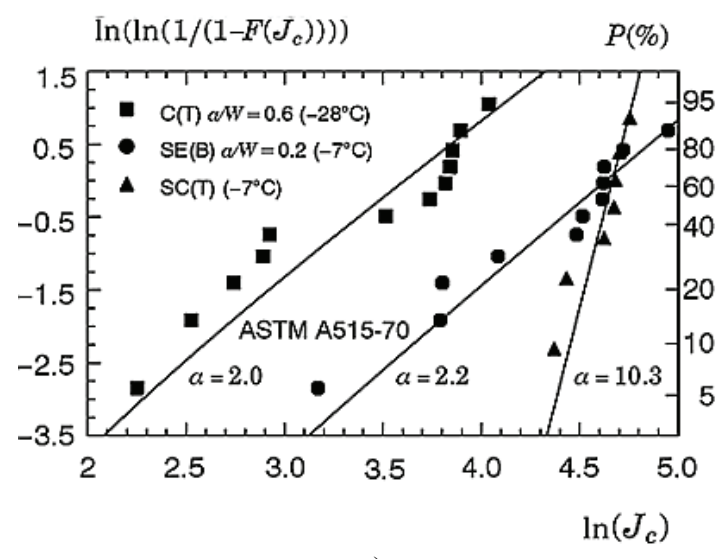

a)

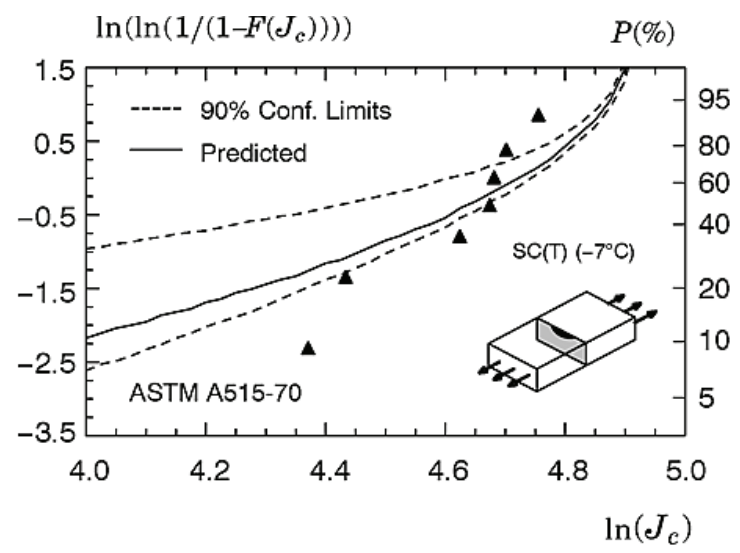

b)

Figure 7. (a) Weibull plots of experimental toughness values at temperatures $-7^{\circ} \mathrm{C}$ and $-28^{\circ} \mathrm{C}$ for the $\mathrm{A515-70}$ pressure vessel steel; (b) Cleavage fracture predictions for the $\mathrm{SC}(\mathrm{T})$ specimen at $-7^{\circ} \mathrm{C}$ for the A515-70 pressure vessel steel.

\section{Parameter Calibration}

The parameter calibration scheme described earlier is applied to determine the Weibull stress parameters for the tested pressure vessel steel. Here, the plastic strain correction is not adopted, so that $\gamma=0$ in previous Eq. (12) defining the Weibull stress. The Weibull modulus, $m$, is calibrated using the deep notch $\mathrm{C}(\mathrm{T})$ specimens and the shallow notch $\mathrm{SE}(\mathrm{B})$ specimens. Because the specimens were not tested at the same temperature, the present methodology adopts a simple procedure to correct the measured toughness values for temperature. By using the Master Curve procedure given by ASTM E-1921 (ASTM, 2008), the $J_{0}$-value for the C(T) specimens at $T=-28{ }^{\circ} \mathrm{C}$ is scaled to corresponding $J_{0}$-value at $T=-7^{\circ} \mathrm{C}$. Moreover, since the toughness values for this specimen are below the limit value $K_{J c}=\sqrt{E b_{0} \sigma_{0} / M}$ with the deformation limit $M=30$ given by ASTM E-1921, they are taken directly as SSY toughness values at $T=-28^{\circ} \mathrm{C}$. The characteristic toughness values for the $\mathrm{C}(\mathrm{T})$ and $\mathrm{SE}(\mathrm{B})$ specimens at $T=-7^{\circ} \mathrm{C}$ are then given as: $J_{0}^{C(T)} \approx 54 \mathrm{~kJ} / \mathrm{m}^{2}$ and $J_{0}^{S E(B)} \approx 102 \mathrm{~kJ} / \mathrm{m}^{2}$. 


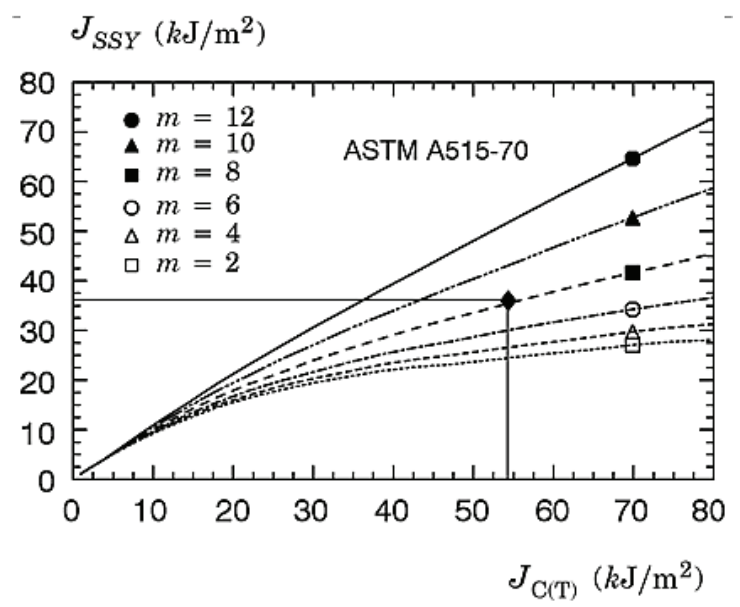

a)

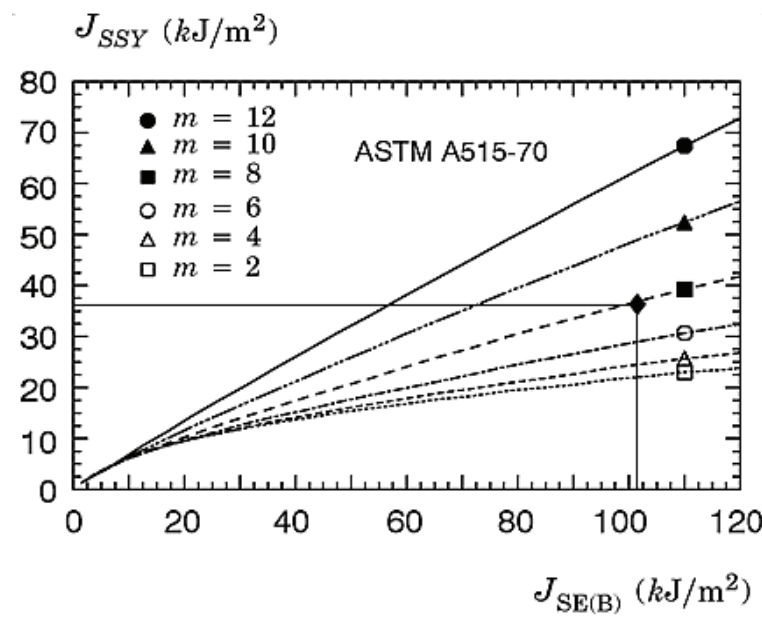

b)

Figure 8. Calibration procedure for the Weibull modulus, $m$, using constraint correction curves at $-7^{\circ} \mathrm{C}$ for the $\mathrm{A515-70}$ pressure vessel steel: (a) C(T) specimen; (b) SE(B) specimen.

With the toughness values for the $\mathrm{C}(\mathrm{T})$ and $\mathrm{SE}(\mathrm{B})$ specimens set at the same temperature $\left(T=-7^{\circ} \mathrm{C}\right)$ and using $\sigma_{w}$ vs. $J$ curves constructed from the 3-D finite element analyses for both crack configurations, the calibration procedure is then applied to determine the $m$-value that yields the same $\sigma_{w}$-value for the pair $\left(J_{0}^{C(T)}, J_{0}^{S E(B)}\right)$. Figure 8 provides constraint correction curves, $J_{S S Y}$ vs. $J_{C(T)}$ and $J_{S S Y}$ vs. $J_{S E(B)}$, for both specimen geometries with different $m$-values. The calibration process is illustrated in the plot by solid lines which indicate the $m$-value that produces a unique value $J_{0}^{S S Y}$ corresponding to the pair $\left(J_{0}^{C(T)}, J_{0}^{S E(B)}\right)$ at $T=-7{ }^{\circ} \mathrm{C}$. Here, the calibrated Weibull modulus for the tested A515 pressure vessel steel is $m \approx 8$.

\section{Fracture Predictions}

To verify the predictive capability of the Weibull stress methodology adopted in the present work, this section describes application of the toughness scaling model based on the Weibull stress $\left(\sigma_{w}\right)$ to predict the toughness distribution for the bolt-loaded surface crack specimen. Very detailed 3-D, nonlinear finite element analyses provide crack front stress fields to generate the evolution of $\sigma_{w}$ vs. $J$ for the $m$-value calibrated in the previous section. Here, because the crack front length of the SC(T) specimen equals 1.67 times the crack front length of the $1(\mathrm{~T})$ specimens (Weisstein, 2010), the corresponding Weibull stress must be scaled to the length of the semi-elliptical crack front.

The Weibull probability plot in Fig. 7(b) shows the predicted distributions of cleavage fracture toughness for the bolt-loaded surface crack specimen. The solid symbols in the plot indicate the measured cleavage fracture toughness $\left(J_{c}\right)$ for this specimen. Values of cumulative probability, $F$, are obtained by ordering the $J_{c}$-values and using $F=(i-0.3) /\left(N_{J}+0.4\right)$, where $i$ denotes the rank number and $N_{J}$ defines the total number of experimental toughness values. The solid line on each figure represents the predicted Weibull distribution generated from the distribution (not individual values from tested specimens) of toughness values for the $\mathrm{C}(\mathrm{T})$ specimen with $a / W=0.6$ using a Monte Carlo procedure (Mann et al., 1974). The dashed lines represent the $90 \%$ confidence bounds generated from the $90 \%$ confidence limits for the calibrated $m$-value (Thoman et al., 1969).

The effectiveness of the present model in describing general fracture behavior for this specimen is clear as the predicted distribution of fracture toughness displayed in Fig. 7(b) agrees well with the experimental data. Here, the $90 \%$ confidence bounds bracket most of the measured toughness values in the mid-region of the curves. The results also indicate that the predicted curves: (1) overpredict the failure probability in the lower tail of the plots and (2) underpredict the failure probability in the upper tail of the plots. However, it should be emphasized that the toughness distribution for the bolt-loaded $\mathrm{SC}(\mathrm{T})$ specimen differs significantly from the toughness distribution for the shallow notch $\mathrm{SE}(\mathrm{B})$ specimen even though both specimens have similar levels of characteristic toughness (recall that the Weibull slopes for the toughness distributions of these specimens displayed in Fig. 7(a) are very different). Nevertheless, the overall error appears sufficiently small to support application of the Weibull stress methodology in the fracture predictions analyzed here.

\section{Prediction of Failure Load in the API X80 Girth Weld}

\section{Experimental Program}

Minami et al. (1995) reported on a series of fracture tests conducted on weld specimens made of an API X80 pipeline steel. The welding procedure and welding conditions follow closely those employed in girth welds made in field conditions. Figure 5 shows the tested weld configurations which include deeply notched SE(B) fracture specimens and a wide plate $\mathrm{SC}(\mathrm{T})$ specimen with a semielliptical, surface center crack with varying levels of weld strength mismatch: evenmatch $\left(M_{y}=1.02\right)$ and $10 \%$ overmatch ( $M_{y}=1.09$ ). The SE(B) specimens have $a / W=0.5$ with thickness $B=25 \mathrm{~mm}$, width $W=25 \mathrm{~mm}$ and span distance $S=100 \mathrm{~mm}$. The wide plate specimens have thickness $t=25 \mathrm{~mm}$, width $2 \mathrm{~W}=400$ $\mathrm{mm}$ and length $L=300 \mathrm{~mm}$; here, the surface crack has length $2 c=100 \mathrm{~mm}$ and depth $a=6 \mathrm{~mm}(a / t=0.24$ and $c / a=8.3)$. In all fracture specimens, the weld groove width, $2 h$, is $10 \mathrm{~mm}$.

The weld specimens were prepared using standard GMAW procedure with heat inputs ranging from 0.3 to $0.9 \mathrm{~kJ} / \mathrm{mm}$ according to the pass sequence (see details in Minami et al., 1995). Mechanical tensile tests extracted from the longitudinal weld direction provide the stress-strain data at room $\left(20^{\circ} \mathrm{C}\right)$ and test temperature $\left(-5^{\circ} \mathrm{C}\right)$. At room temperature, the evenmatch weld has 
yield stress, $\sigma_{y s}=581 \mathrm{Mpa}$, and tensile strength, $\sigma_{u t s}=670 \mathrm{MPa}$. The $10 \%$ overmatch weld has yield stress, $\sigma_{y s}=621 \mathrm{MPa}$, and tensile strength, $\sigma_{u t s}=691 \mathrm{MPa}$. The degree of weld strength mismatch is essentially similar to the mismatch level at room temperature. Moreover, both materials display relatively low strain hardening $\left(\sigma_{u t s} / \sigma_{y s} \approx 1.11 \sim 1.15\right.$ ) so that effects of hardening mismatch are considered negligible. Other mechanical properties for this material include Young's modulus, $E=206 \mathrm{GPa}$ and Poisson's ratio, $v=0.3$. Minami et al. (1995) provide further details on the mechanical tensile test data for this material.

Testing of the $\mathrm{SE}(\mathrm{B})$ specimens was performed at $T=-5^{\circ} \mathrm{C}$ which is within the range of the ductile-to-brittle transition behavior for the material. Records of load vs. crack mouth opening displacements (CMOD) were obtained for each specimen using a clip gauge mounted on knife edges attached to the specimen surface. Post-test examinations established the amount of stable crack growth prior to final fracture by cleavage. Figure 9(a) shows the effect of strength mismatch on the measured $J_{c}$-values. The toughness values for the $10 \%$ overmatch specimens exceed the evenmatch toughness by a factor of 1.5 2.0. Figure 9(b) provides a Weibull diagram of the measured toughness values for both sets of data. The solid symbols in the plot indicate the measured cleavage fracture toughness $\left(J_{c}\right)$ for this specimen. Values of cumulative probability, $F$, are obtained by ordering the $J_{c}$-values and using $F=(i-0.3) /\left(N_{J}+0.4\right)$, where $i$ denotes the rank number and $N_{J}$ defines the total number of experimental toughness values. The straight lines indicate the two-parameter Weibull distribution, Eq. (1) with $J_{t h}=0$, obtained by a maximum likelihood analysis (Mann et al., 1974) of the data set with a fixed Weibull slope of $\alpha=2$.

Fracture testing was also conducted on the wide plate specimens with a $10 \%$ overmatch girth weld at $T=-5^{\circ} \mathrm{C}$. Records of overall (remote) strain, $\varepsilon_{r}$, vs. crack mouth opening displacements (CMOD) were obtained using 4 strain gages conveniently attached at a distance of $100 \mathrm{~mm}$ from the notch on both sides of the plate. The specimen failed by overload fracture after some amount of ductile tearing; here, the experimentally measured failure strain (average of the strain gage readings) is given by $\varepsilon_{f}=2.25 \%$ (Minami et al., 1995).

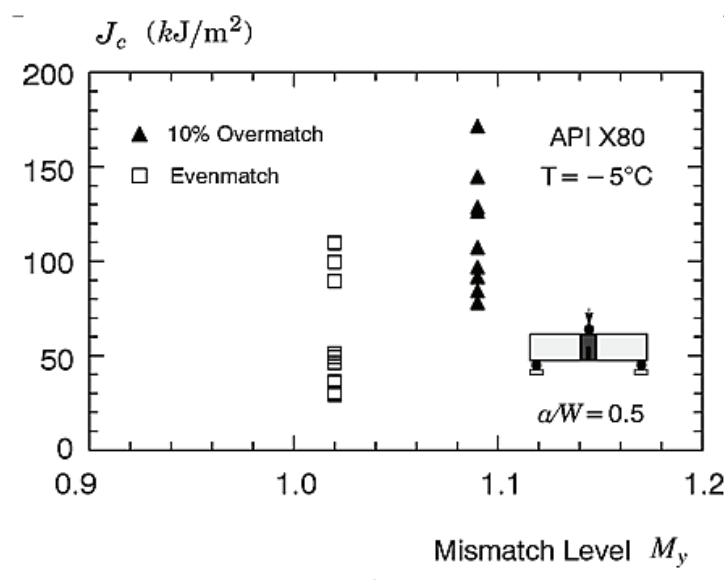

a)

Figure 9. (a) Experimental toughness values for welded deep crack $S E(B)$ fracture specimens of API X80 steel with two mismatch $\left(5^{\circ} \mathrm{C}\right)$; (b) Weibull distribution of toughness values for the experimental data set of the $S E(B)$ fracture specimens.

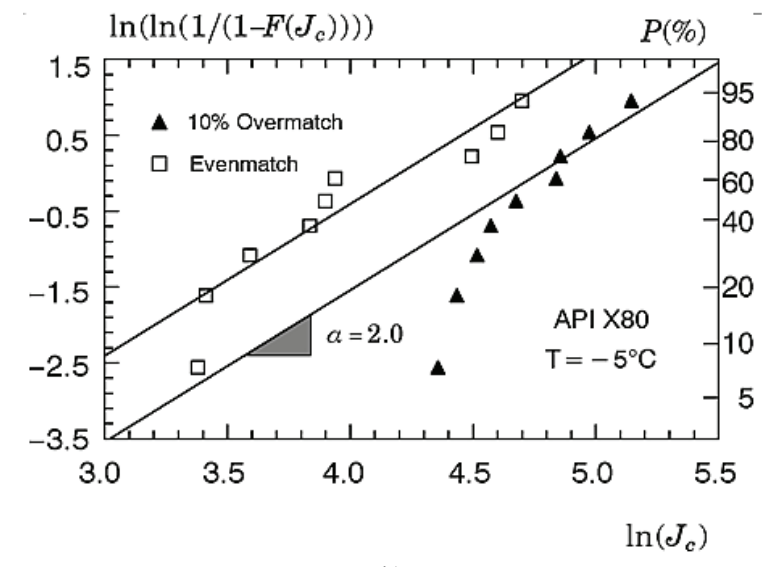

b)

Figure 9. (Continued).

\section{Weibull Modulus Calibration for the Tested Weldment}

The parameter calibration scheme described previously is applied to determine the Weibull modulus for the tested weldment. In the present application, calibration of parameter $m$ is conducted by scaling the mean value of the measured toughness distribution for the evenmatch $\mathrm{SE}(\mathrm{B})$ specimen (taken here as the "baseline" value) to an equivalent mean value of the toughness distribution for the $10 \%$ overmatch $\mathrm{SE}(\mathrm{B})$ specimen. The calibration process simply becomes a means of determining an $m$-value that corrects the nondimensional characteristic toughness value for the evenmatch specimen, denoted $\bar{J}_{0, S E(B)}^{E v e n}$, to its equivalent value for overmatch specimen, $\bar{J}_{0, S E(B)}^{\text {Over }}$.

As further refinement, the procedure also considers the influence of the plastic strain correction on the Weibull stress and, consequently, on the calibrated Weibull modulus for the tested material. For the purpose of assessing the effectiveness of Eq. (12) in predictions of the failure strain for the wide plated conducted next, the present investigation considers two sets of widely different parameters defining the microcrack density: $i$ ) $\gamma=0$ (no plastic strain correction) and ii) $\gamma=1$ and $\beta=0$ which implies a simple linear dependence of microcrack density on the plastic strain. While this choice of parameters $\gamma$ and $\beta$ is somewhat arbitrary, it does make contact with the experimental findings of Lindley et al. (1970) and Gurland (1972) in ferritic steels.

Very detailed finite element computations of these specimens enable construction of the $\bar{J}_{0, S E(B)}^{E v e n} \rightarrow \bar{J}_{0, S E(B)}^{O v e r}$ correction shown in Fig. 10(a)-(b) for varying $m$-values. In both plots, each curve provides pairs of $J$-values corresponding to the $10 \%$ overmatch and evenmatch $\mathrm{SE}(\mathrm{B})$ specimen that produce the same nondimensional $\bar{\sigma}_{w}$. The Weibull modulus does affect predictions of mismatch effects; here, changing the $m$-value assigns a different weight factor to stresses at locations very near to the crack front thereby altering the ratio of mismatch correction. A closer inspection of these plots also reveals that the toughness scaling curves for the fracture specimens and mismatch levels considered display only a weak dependence on the adopted plastic strain correction. Because the crack geometry and degree of mismatch for both fracture specimens do not differ significantly, this behavior is not unexpected since the near-tip strain fields for both the evenmatch and overmatch specimens under analysis should be relatively similar. 
The calibration scheme now proceeds by adopting a twoparameter Weibull function given by Eq. (1) with $\alpha=2$ and $J_{t h}=0$ to describe the toughness distribution. Here, the characteristic toughness values for the evenmatch and overmatch bend specimens are $J_{0, S E(B)}^{E v e n} \approx 67 \mathrm{~kJ} / \mathrm{m}^{2}$ and $J_{0, S E(B)}^{O v e r} \approx 118 \mathrm{~kJ} / \mathrm{m}^{2}$. Once the $m-$ values for each mismatch condition is determined, the calibration procedure then yields the Weibull modulus of the tested material at $T=-5{ }^{\circ} \mathrm{C}$ for the two cases considered in the present study: $i$ ) $m=13.5$ for $\gamma=0$ (no plastic strain correction) and ii) $m=15.0$ for $\gamma=1$ and $\beta=0$ (linear plastic strain correction). Figure 10 recasts the calibration strategy into a graphical procedure for both cases considered to determine parameter $m$ using the scaling curves displayed in that plot. Again, these calibrated $m$-values are similar and exhibit a relatively minor dependence on the adopted plastic strain correction.

\section{Failure Strain Prediction for the Welded Plate}

To verify the predictive capability of the Weibull stress methodology adopted in the present work, this section describes application of the toughness scaling model based on the nondimensional Weibull stress $\left(\bar{\sigma}_{w}\right)$ incorporating effects of weld strength mismatch and plastic strain to predict the failure strain for the clamped surface crack $\mathrm{SC}(\mathrm{T})$ specimen with $10 \%$ overmatch. Very detailed nonlinear finite element analyses provide the crack front stress fields to generate the evolution of $\bar{\sigma}_{w}$ vs. $\bar{J}$ for the $m$-values calibrated in the previous section. Here, the $J$-value at failure for the tested $\mathrm{SC}(\mathrm{T})$ specimen, $\bar{J}_{0, S C(T) \text {, and the }}^{\text {Over }}$ corresponding failure strain are predicted using the measured deep crack toughness values for the evenmatched SE(B) specimen translated in terms of the (nondimensional) characteristic toughness, $\bar{J}_{0, S E(B)}^{\text {Even }}$.

Figures 11(a)-(b) show the computed evolution of $\bar{\sigma}_{w}$ under increasing values of $\bar{J}$ for the $\mathrm{SE}(\mathrm{B})$ and $\mathrm{SC}(\mathrm{T})$ configurations using the plastic strain correction model with the calibrated $m$ values. Figure 12 displays the mechanical response of the $\mathrm{SC}(\mathrm{T})$ specimen characterized in terms of the evolution of remote applied strain, $\varepsilon_{r}$, with increased (nondimensional) crack-tip loading, $\bar{J}$. These curves provide the quantitative basis to predict the failure strain for the surface crack specimen with $10 \%$ overmatch. Here, because the crack front length of the $\mathrm{SC}(\mathrm{T})$ specimen is 4 times the crack front length of the SE(B) specimen (Weisstein, 2010), the $\bar{\sigma}_{w}$-values for the bend specimen must be scaled to the length of the semi-elliptical crack front for the wide plate specimen to guarantee that similar volumes of the (near-tip) fracture process zone are included into the computation of the Weibull stress for each crack configuration (see Eq. (12)).

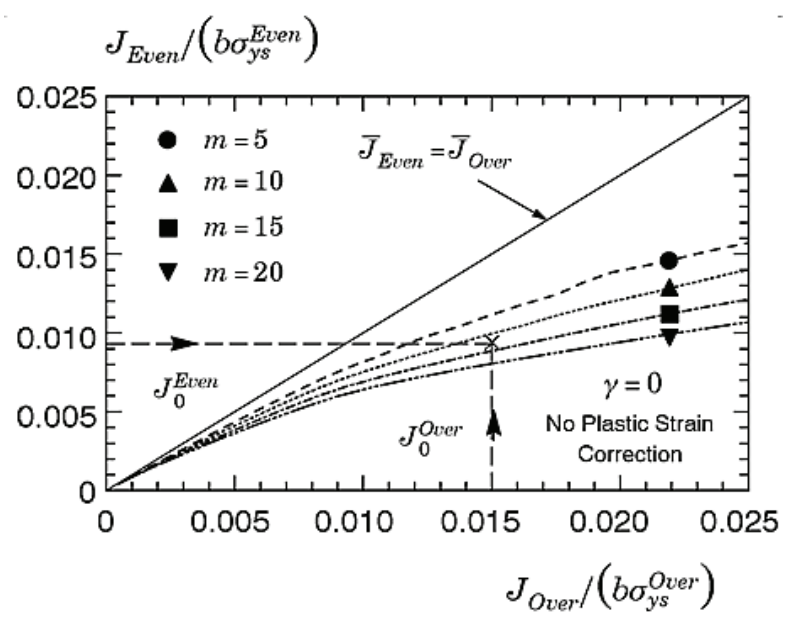

a)

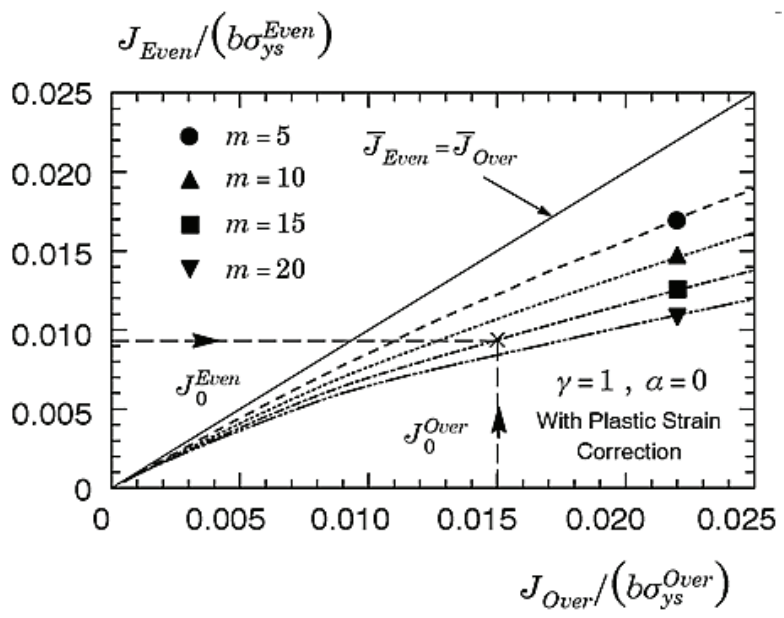

b)

Figure 10. Toughness correction using the TSM methodology based upon the nondimensional Weibull stress with varying Weibull moduli for the tested welded SE(B) fracture specimens.

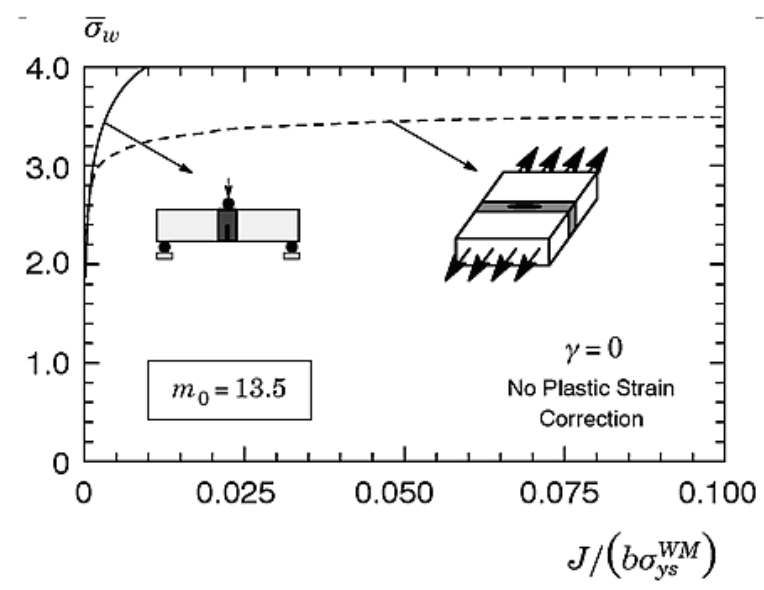

a)

Figure 11. Nondimensional Weibull stress trajectories with nondimensional $J$ for the evenmatch $S E(B)$ and the overmatch $S C(T)$ specimen for the calibrated m-values. 


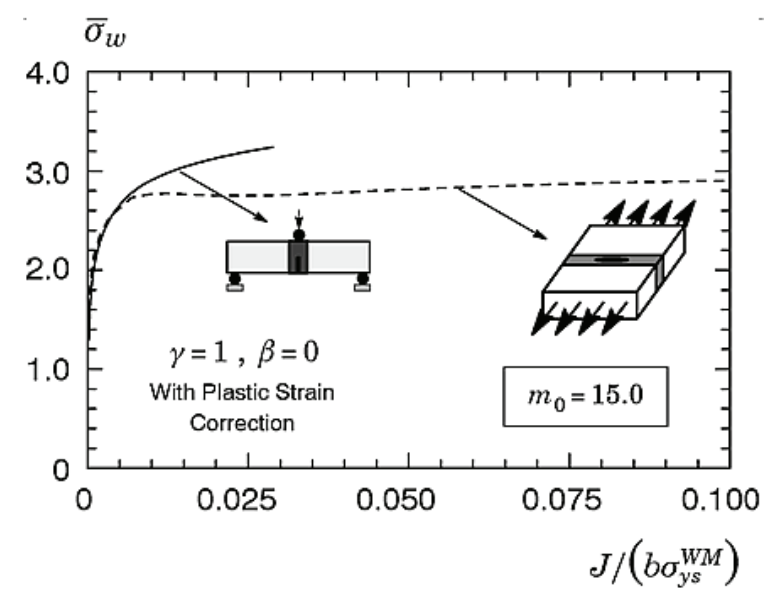

b)

Figure 11. (Continued).

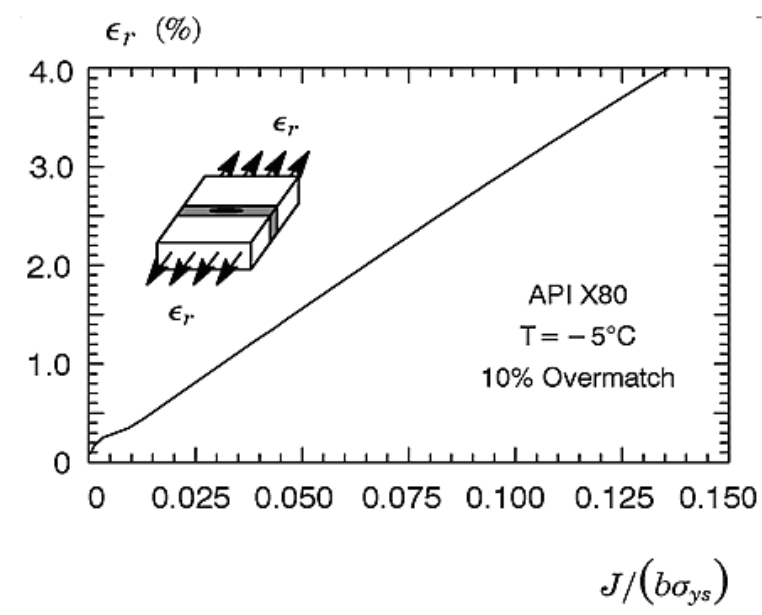

Figure 12. Evolution of remote applied strain with increased nondimensional $\mathrm{J}$ for overmatch $\mathrm{SC}(\mathrm{T})$ specimen.

Using again the TSM procedure outlined previously, prediction of the failure strain for the $\mathrm{SC}(\mathrm{T})$ specimen proceeds as follows. First, the characteristic $\bar{J}_{0}$-value for the $10 \%$ overmatch $\mathrm{SC}(\mathrm{T})$ specimen is determined based upon the $\bar{J}_{0}$-value for the evenmatch $\mathrm{SE}$ (B) specimen. The failure strain is then evaluated by means of the computed strain-crack driving force relationship for the wide plate specimen. As a further refinement, the $90 \%$ confidence limits for the $\bar{J}_{0}$-value of the evenmatch $\mathrm{SE}$ (B) specimen are also employed to estimate the corresponding $90 \%$ confidence bounds for the failure strain of the $\mathrm{SC}(\mathrm{T})$ specimen.

Consider first the nondimensional Weibull stress trajectories with no plastic strain correction displayed in Fig. 11(a). While $\bar{\sigma}_{w}$ for the evenmatch $\mathrm{SE}(\mathrm{B})$ specimen shows a marked increase with $\bar{J}$, the Weibull stress for the $\mathrm{SC}(\mathrm{T})$ specimen rises at a much lower rate with increased levels of crack-tip loading. Given the expected toughness ratio $\left(\bar{J}_{0, S E(B)}^{\text {Even }} / \bar{J}_{0, S C(T)}^{\text {Over }}\right)$ of $\approx 10 \sim 15$ for these two data sets, the analysis clearly fails to predict the failure strain for the $\mathrm{SC}(\mathrm{T})$ specimen. Consider now the evolution of $\bar{\sigma}_{w}$ vs. $\bar{J}$ incorporating the effect of plastic strain displayed in Fig. 11(b). With the introduction of the adopted plastic strain correction, a different picture now emerges which can be summarized as follows:
1) The $\bar{\sigma}_{w}$ vs. $\bar{J}$ trajectory for the evenmatch $\mathrm{SE}(\mathrm{B})$ specimen increases rapidly in the initial stage of crack-tip deformation and then more slowly as crack-tip deformation continues and 2) The overmatch $\mathrm{SC}(\mathrm{T})$ specimen also displays a slowly rising Weibull stress curve, but which is now fully consistent with the toughness ratio for the analyzed data sets. Based upon the $\bar{\sigma}_{w}$ vs. $\bar{J}$ trajectories displayed in Fig. 11(b) and the plot of $\varepsilon_{r}$ vs. $\bar{J}$ displayed in Fig. 12, the predicted failure strain, $\varepsilon_{\text {pred }}$, and corresponding $90 \%$ confidence bounds (Thoman et al., 1969) are $\varepsilon_{\text {pred }}=2.27 \%(1.2 \% ; 3,6 \%)$. Even though Minami et al. (1995) report only a single value for the experimental failure strain, the ability of the present model in describing the fracture behavior for the overmatch $\mathrm{SC}(\mathrm{T})$ specimen seems evident as the predicted failure strain and the $90 \%$ confidence bounds agree very well with the experimental data.

\section{Summary and Conclusions}

This work describes the development of a probabilistic framework and a toughness scaling methodology incorporating the effects of constraint loss and weld strength mismatch on crack-tip driving forces. The approach builds upon a micromechanics description of the cleavage fracture process using the Weibull stress, $\sigma_{w}$, as a near-tip driving force coupled to a convenient description of the toughness scaling model. For the same material at a fixed temperature, the scaling model requires the attainment of a specified value for $\sigma_{w}$ to trigger cleavage fracture across cracked configurations, including weldments, even though the corresponding $J(\delta)$-values may differ widely. A key feature of this methodology is that $\sigma_{w}$ incorporates both the effects of stressed volume (the fracture process zone) and the potentially strong changes in the character of the near-tip stress fields due to constraint loss (and weld strength mismatch). The procedure is naturally suited for implementations coupled with finite element codes so that different constitutive properties as well as strain rate and thermal effects can easily be addressed. Application of the methodology to predict cleavage fracture behavior in pressure vessel steel tested in the transition region agrees well with experimental data. Moreover, extension of the procedure to predict the failure strain for an overmatch girth weld made of an API X80 pipeline steel clearly demonstrates the effectiveness of the micromechanics approach. Overall, the results lend strong support to use a Weibull stress based procedure in defect assessments of structural components.

\section{Acknowledgements}

This investigation is supported by the Brazilian Council for Scientific and Technological Development (CNPq). The author acknowledges Prof. F. Minami from Osaka University for making the girth weld data for the API X80 steel available.

\section{References}

Al-Ani, A.M., and Hancock, J.W., 1991, "J-Dominance of Short Cracks in Tension and Bending", Journal of Mechanics and Physics of Solids, Vol. 39, pp. 23-43.

American Society for Testing and Materials, 2008, "Standard Test Methods for Determination of Reference Temperature, T0, for Ferritic Steels in the Transition Range", ASTM E-1921, Philadelphia.

Anderson, T.L., 2005, "Fracture Mechanics: Fundaments and Applications" - 3rd Edition, CRC Press, New York.

Averbach, B.L., 1965, "Micro and Macro Crack Formation", International Journal of Fracture Mechanics, Vol. 1, pp. 272-290. 
Batdorf, S.B. and Crose, J.G., 1974, "A Statistical Theory for the Fracture of Brittle Structures Subjected to Nonuniform Polyaxial Stresses", Journal of Applied Mechanics, Vol. 41, pp. 459-464.

Beremin, F.M, 1983, "A Local Criterion for Cleavage Fracture of a Nuclear Pressure Vessel Steel", Metallurgical Transactions, Vol. 14A, pp. 2277-2287

Betegon, C., and Hancock, J.W., 1991, "Two-Parameter Characterization of Elastic-Plastic Crack Tip Fields", Journal of Applied Mechanics, Vol. 58, pp. 104-113.

Brindley, B. J., 1970, "The Effect of Dynamic Strain-Aging on the Ductile Fracture Process in Mild Steel", Acta Metallurgica, Vol. 18, pp. 325-329.

Brückner-Foit, A., Ehl, W., Munz, D. and Trolldenier, B, 1990, "The Size Effect of Microstructural Implications of the Weakest Link Model", Fatigue and Fracture of Engineering Materials and Structures, Vol. 13, pp. $185-200$.

Du, Z.-Z., and Hancock, J.W., 1991, "The Effect of Non-Singular Stresses on Crack-Tip Constraint", Journal of Mechanics and Physics of Solids, Vol. 39, pp. 555-567, 1991.

Evans, A.G., 1978, "A General Approach for the Statistical Analysis of Multiaxial Fracture", Journal of American Ceramic Society, Vol. 61, pp. 302-308.

Evans, A.G. and Langdon, T.G., 1976, "Structural Ceramics" in Progress in Materials Science, Volume 21, Ed. B. Chalmers, pp. 171-441, Pergamon Press, NY.

Feller, W., 1957, "Introduction to Probability Theory and Its Application", Vol. I, John Wiley \& Sons, Inc. New York.

Freudenthal, A.M, 1968, "Statistical Approach to Brittle Fracture" in Fracture: An Advanced Treatise. Volume II, Ed. H. Liebowitz, pp. 592-619, Academic Press, NY.

Gao,X., Dodds, R.H., Tregoning, R.L., Joyce, J.A. and Link, R.E., 1999, "A Weibull Stress Model to Predict Cleavage Fracture in Plates Containing Surface Cracks", Fatigue and Fracture of Engineering Materials and Structures, Vol. 22, pp. 481-493.

Gao,X., Ruggieri, C. and Dodds, R.H., 1998, "Calibration of Weibull Stress Parameters Using Fracture Toughness Data", International Journal of Fracture, Vol. 92, pp. 175-200.

Godse, R. and Gurland, J., 1989, "A Statistical Model for Low Temperature Cleavage Fracture in Mild Steels", Acta Metallurgica, Vol. 37, pp. 541-548.

Gullerud, A., Koppenhoefer, K., Roy, A., RoyChowdhury, S., Walters, M., Bichon, B., Cochran, K. and Dodds, R., 2004, "WARP3D: Dynamic Nonlinear Fracture Analysis of Solids Using a Parallel Computers and Workstations". Structural Research Series (SRS) 607. UILU-ENG-95-2012. University of Illinois at Urbana-Champaign.

Gurland, J., 1972, "Observations on the Fracture of Cementite Particles in a Spheroidized $1.05 \%$ C Steel Deformed at Room Temperature", Acta Metallurgica, Vol. 20, pp. 735-741.

Hutchinson, J.W., 1983, "Fundamentals of the Phenomenological Theory of Nonlinear Fracture Mechanics", Journal of Applied Mechanics, Vol. 50, pp. 1042-1051

Joyce, J.A. and Link, R.E., 1997, "Ductile-to-Brittle Transition Characterization Using Surface Crack Specimens Loaded in Combined Tension and Bending", in Fatigue and Fracture Mechanics: 28th Volume, ASTM STP 1321, J. H. Underwood, et al. Eds., American Society for Testing and Materials, Philadelphia, pp. 243-262.

Kendall, M.G. and Stuart, A., 1967, "The Advanced Theory of Statistics", 2nd ed., Hafner, New York.

Lin, T., Evans, A.G. and Ritchie, R.O., 1986, "A Statistical Model of Brittle Fracture by Transgranular Cleavage", Journal of Mechanics and Physics of Solids, Vol. 21, pp. 263-277.

Lindley, T.C., Oates, G. and Richards, C.E., 1970, “A Critical Appraisal of Carbide Cracking Mechanism in Ferride/Carbide Aggregates", Acta Metallurgica, Vol. 18, pp. 1127-1136.

Mann, N.R., Schafer, R.E. and Singpurwalla, N.D., 1974, "Methods for Statistical Analysis of Reliability and Life Data", Jonh Wiley \& Sons, New York.
Matsuo, Y., 1981, "Statistical Theory for Multiaxial Stress States Using Weibull's Three-Parameter Function", Engineering Fracture Mechanics, Vol. 14, pp. 527-538.

Minami, F., Brückner-Foit, A., Munz, D. and Trolldenier, B., 1992, "Estimation Procedure for the Weibull Parameters Used in the Local Approach", International Journal of Fracture, Vol. 54, pp. 197-210.

Minami, F., Ohata, M., Toyoda, M., Tanaka, T., Arimochi, K., Glover, A.G. and North, T.H., 1995, "The Effect of Weld Metal Yield Strength on the Fracture Behavior of Girth Welds in Grade 550 Pipe", Pipeline Technology, Vol. 1, pp. 441-461.

Moran, B., and Shih, C.F., 1987, "A General Treatment of Crack Tip Contour Integrals", International Journal of Fracture, Vol. 35, pp. 295-310.

Mudry, F., 1987, "A Local Approach to Cleavage Fracture”, Nuclear Engineering and Design, Vol. 105, pp. 65-76.

O'Dowd, N.P., and Shih, C.F., 1991, "Family of Crack-Tip Fields Characterized by a Triaxiality Parameter: Part I - Structure of Fields", Journal of the Mechanics and Physics of Solids, Vol. 39., No. 8, pp. 989-1015.

Nevalainen, M., and Dodds, R. H., 1995, "Numerical Investigation of 3D Constraint Effects on Brittle Fracture in SE(B) and C(T) Specimens", International Journal of Fracture, Vol. 74, pp. 131-161.

O'Dowd, N.P., and Shih, C.F., 1992, "Family of Crack-Tip Fields Characterized by a Triaxiality Parameter: Part II - Fracture Applications", Journal of the Mechanics and Physics of Solids, Vol. 40, pp. 939-963.

Parks, D.M., 1992, "Advances in Characterization of Elastic-Plastic Crack-Tip Fields", in Topics in Fracture and Fatigue, A.S. Argon, Ed., Springer Verlag, pp. 59-98.

Ruggieri, C., 1989, "Probabilistic Analysis of Fracture in Heterogeneous Materials and Extension to Failure Assessments of Welded Structures", M.Sc. Thesis, University of São Paulo, Polytechnic School, 198 p. (in Portuguese).

Ruggieri, C., 2001, "Influence of Threshold Parameters on Cleavage Fracture Predictions Using the Weibull Stress Model", International Journal of Fracture, Vol. 110, pp. 281-304.

Ruggieri, C., 2001, "WSTRESS Release 2.0: Numerical Computation of Probabilistic Fracture Parameters for 3-D Cracked Solids", Technical Report BT-PNV-51, EPUSP, University of São Paulo.

Ruggieri, C. and Dodds, R.H., 1996, "A Transferability Model for Brittle Fracture Including Constraint and Ductile Tearing Effects: A Probabilistic Approach", International Journal of Fracture, Vol. 79, pp. 309-340.

Ruggieri, C. and Dodds, R.H., 1996, "Probabilistic Modeling of Brittle Fracture Including 3-D Effects on Constraint Loss and Ductile Tearing", Journal de Physique, Vol. 6, pp. 353-362.

Ruggieri, C., Gao, X. and Dodds, R.H., 2000, "Transferability of Elastic-Plastic Fracture Toughness Using the Weibull Stress Approach: Significance of Parameter Calibration”, Engineering Fracture Mechanics, Vol. 67, pp. 101-117.

Tetelman, A.S. and McEvily, A.J., 1967, "Fracture of Structural Materials", John Wiley \& Sons, New York.

Thoman, D.R., Bain, L.J. and Antle, C.E., 1969, "Inferences on the Parameters of the Weibull Distribution", Technometrics, Vol. 11, pp. 445-460.

Wallin, K., Saario, T., and Torronen, K., 1984, "Statistical Model for Carbide Induced Brittle Fracture in Steel," Metal Science, Vol. 18, pp. 13-16.

Wallin, K., 1984, "The Scatter in $K_{I c}$ Results", Engineering Fracture Mechanics, Vol. 19, pp. 1085-1093.

Wallin, K., 1993, "Statistical Aspects of Constraint with Emphasis on Testing and Analysis of Laboratory Specimens in the Transition Region", in Constraint Effects in Fracture, ASTM STP 1171, Hackett, et al. Eds., American Society for Testing and Materials, Philadelphia, pp. 264-288.

Wallin, K., Saario, T., Torronen, K. and Forstén, J., 1986, "Brittle Fracture Theory (WST Model)", in Reliability of Reactor Materials. Fracture Mechanics, Research Report 402, K. Törrönen and I. Aho-Mantila, Eds., Technical Research Center of Finland.

Weibull, W., 1951, "A Statistical Distribution Function of Wide Applicability", Journal of Applied Mechanics, Vol. 18, pp. 293-297.

Weisstein, E.W., 2010, "Ellipse", in MathWorld - A Wolfram Web Resource. http://mathworld.wolfram.com/Ellipse.html. 